\title{
Doblemente sometidas: las «mujeres de color» en la república de Cuba (1902-1959) ${ }^{1}$
}

\author{
por \\ Manuel Ramírez Chicharro \\ Instituto de Historia-CSIC
}

\begin{abstract}
El estudio analiza la trayectoria de las mujeres afrodescendientes durante la República de Cuba (1902-1959). En primer lugar, se realiza una valoración de las obras dedicadas a las mujeres cubanas como género, por un lado, y a la cultura afro, por otro, para demostrar hasta qué punto las mujeres afrocubanas han sido desatendidas por la historiografía. Después se pasa a examinar a las mujeres negras y mestizas en relación con la población masculina total y las mujeres blancas. El texto se divide en tres apartados: campo educativo, inserción laboral y movilidad politica. Los datos permiten afirmar que las mujeres afrocubanas estuvieron doblemente sometidas durante todo el perído republicano, por género frente a los hombres negros, por "raza» frente a las mujeres blancas.
\end{abstract}

PALABRAS Clave: afrocubanas; república de Cuba; género; raza; feminismo.

\section{INTRODUCCIÓN}

Este artículo trata de estudiar algunos parámetros para constatar la doble marginación que padecieron las mujeres afrodescendientes durante la República de Cuba, por «raza» frente a la población negra, por género frente a las mujeres blancas. Para ello, se han tomado como fuentes principales los censos estadísticos nacionales que permiten diferenciar los datos en categorías de sexo y «raza» $(1907,1919$ y 1943), algunos periódicos y revistas de la época,

${ }^{1}$ Este artículo ha sido elaborado en el marco del proyecto HAR2012-37455-C03-01 (MINECO), "Marcadores del tiempo: Continuidades y discontinuidades en las sociedades hispanoantillanas, siglos XIX y XX", dirigido por Consuelo Naranjo Orovio, Profesora de Investigación del Instituto de Historia del CSIC. 
así como el registro de asociaciones del Archivo Nacional de Cuba. Se ha utilizado la nomenclatura aplicada por los mismos documentos a la hora de diferenciar a las mujeres según la «raza». La mayoría de ocasiones se alude a «mujeres blancas nativas», «mujeres blancas extranjeras» y «mujeres de color». Este último grupo incluye a personas «negras, mestizas y amarillas», lo que sin embargo no desvirtúa en exceso los resultados obtenidos. Por lo general resulta imposible diferenciar estas subcategorías, excepto en cuestiones demográficas, pero no en lo relativo a los empleos.

La historiografía sobre la República de Cuba ha dedicado escasa atención a la problemática de las mujeres cubanas afrodescendientes durante el siglo XX. Cabe mencionar la ausencia generalizada tanto en obras clásicas, como en los artículos y tesis doctorales cuyo objeto de estudio son las mujeres o a la población afrocubana entre 1902 y 1959. El estudio de Pedro Serviat apenas menciona la mujer a lo largo de su obra ${ }^{2}$. La obra de Jorge e Isabel Castellanos, en el tomo de historia, no dedica ningún apartado específico a las mujeres afrodescendientes. En las últimas páginas del libro se hace mención a la mulata, y solamente para decir que constituía un «símbolo sexual muy extendido entre los varones blancos $»^{3}$. Años más tarde, Tomás Fernández Robaina, en su estudio bibliográfico sobre temas afrocubanos, no contempla ninguna obra dedicada a las mujeres afrodescendientes durante la República y él mismo tampoco incorporó a sus estudios de la negritud la perspectiva de género ${ }^{4}$. Las mujeres afrocubanas también destacan por su ausencia en los dos libros de referencia sobre los movimientos feministas en Cuba, algo que asume la propia Lynn Stonner en la conclusión de su libro ${ }^{5}$. La tesis doctoral defendida por Brenda Liz, en 2013 sobre la cuestión femenina en el Caribe, dedica un capítulo al caso cubano desde 1880 a 1940. Analiza obras literarias y agrupaciones femeninas como un engranaje más del progreso social. Sin embargo, también pasa por alto al sector de mujeres afrocubanas, tanto en el período colonial como en el republicano. Solamente las menciona en dos ocasiones, sin distinguirlas de los varones, bajo el término genérico de «afrodescendientes ${ }^{6}$.

Alejandro de la Fuente esboza en algunos párrafos la situación que atravesaban las mujeres afrocubanas durante el siglo XX. Hace hincapié en la conformación de Clubes de Damas dentro de las asociaciones de afrodescen-

\footnotetext{
2 Serviat, 1986.

3 Castellanos y Castellanos, 1990: 423-429.

4 Fernández Robaina, 1985; 1994.

5 González Pagés, 2001. Lynn Stonner, 2001.

${ }^{6}$ Liz Ortiz-Loyola, 2013: 101-169.
} 
dientes durante la república de $\mathrm{Cuba}^{7}$. En su análisis sobre la población afrocubana desde la abolición de la esclavitud hasta la matanza del Partido Independiente de Color, Aline Helg se refiere a la mujer en lo relativo a la actuación del PIC, haciendo ver que esta agrupación antepuso los intereses raciales y de unidad nacional al progreso de la mujer en las relaciones de género, tanto en el ámbito privado como público ${ }^{8}$. Daisy Rubiera e Inés María Matiatu han reunido a un grupo de investigadoras que abordan diferentes temas históricos, antropológicos, religiosos y literarios sobre las mujeres afrocubanas desde el siglo XIX hasta la actualidad a través del estudio o reproduciendo fuentes primarias 9 . Junto a María de los Reyes Castillo, la propia Daisy Rubiera recoge el testimonio de su madre, una mujer negra que vivió durante la república. A través de su vida, explican la marginación que experimentaron las mujeres afrodescendientes ese período ${ }^{10}$. $\mathrm{Y}$ en otro estudio realiza una aproximación a través de la oralidad a la historia de las mujeres negras durante este mismo período ${ }^{11}$.

Aymée Rivera dedica un artículo a la construcción del imaginario femenino afrocubano, tanto por parte de las propias mujeres, como a través de la mirada de algunos hombres, enfocando su atención sobre los testimonios y las obras literarias de mujeres negras y mestizas. Para ello recurre, mayoritariamente, a autores del siglo XIX o del período revolucionario ${ }^{12}$. Por su parte, Carmen Barcia alude en algunas ocasiones a las mujeres afrocubanas cuando analiza el papel que desempeñaron los sectores populares y marginados en Cuba en la transición sociopolítica desde el siglo XIX al XX, pero sin profundizar en las relaciones de género ${ }^{13}$. Lourdes Serrano aporta un breve estudio, próximo a la microhistoria, acerca de las mujeres negras y mestizas en un barrio de La Habana. Si bien puntualiza algunos datos estadísticos sobre sus niveles de alfabetización y las relaciones interpersonales con los hombres negros y el resto de la población, la mayoría del texto se ocupa de la evolución que experimentaron las mujeres afrodescendientes durante el proceso revolucionario y hasta la actualidad ${ }^{14}$. Carmen Montejo, en su trabajo sobre las sociedades creadas por la población afrodescendientes desde el siglo XIX hasta el período revolucionario, cita ocasionalmente a las mujeres

\footnotetext{
7 Fuente, 2000.

8 Helg, 2000: 148.

9 Rubiera y Matiatu, 2011.

10 Rubiera y De los Reyes, 1997.

11 Rubiera, 2011.

12 Rivera Pérez, 2007.

13 Barcia Zequeira, 2009.

14 Serrano, 2006.
} 
negras y mestizas. Alude a la sección femenina del Club de Atenas y a la vinculación de esta con sus homónimas estadounidenses, como Mary McLeon o Mabel E. Simis. Posteriormente entra a relacionar una serie de mujeres que participaron de la Sección Femenina de la Federación de Sociedades Cubanas de la provincia de La Habana, entre las cuales se pueden encontrar algunas de carácter racial ${ }^{15}$.

Una de las obras que ofrece una información y análisis más amplio sobre la estructura socio-económica de Cuba es el de Jorge Ibarra. En su estudio dedica dos capítulos para analiza las características de la población femenina entre 1898 y 1959, donde también se ocupa de las mujeres negras. Haciendo uso de tablas y análisis estadísticos, ofrece una aproximación a la demografía y los oficios que desempeñaban, no solo las mujeres blancas, sino también las mujeres negras y mestizas ${ }^{16}$. Por su parte, Takkara Keosha realiza un trabajo más conceptual en su reciente tesis doctoral. Tomando a las mujeres afrocubanas como objeto de examen, ofrece una panorámica de su trayectoria como colectivo a lo largo de la república de Cuba. Para ello, hace uso de las herramientas que proporcionan los estudios sobre la «raza», el género y el patriarcado, añadiéndole la vertiente nacionalista que caracterizó a los movimientos regeneracionistas del período ${ }^{17}$.

Resultan escasas las fuentes que permiten estudiar la cuestión de las mujeres afrocubanas durante la República. La legislación que les concierte fue escasa. Los censos aportan algunos datos que deben examinarse de forma pormenorizada para interpretarlos después en su contexto. La prensa afrocubana fue abundante, aunque efímera y mal conservada por lo que es difícil encontrar algunos ejemplares, lo que dificulta la recogida de información. En síntesis, como exponen en sendos estados de la cuestión Consuelo Naranjo y Antonio Santamaría, por un lado, y Marta Sarmiento por otro, hasta el año 2000 es difícil encontrar estudios en Cuba que aborden la cuestión de las mujeres afrodescendientes durante la república de $\mathrm{Cuba}^{18}$. Esto no puede achacarse solamente al desinterés de la comunidad científica. Más bien podría apelarse a otros dos condicionantes. Primero, la carencia de fuentes generadas y conservadas que permitan estudiarlo con metodología histórica. Segundo, la poca relevancia otorgada desde las instancias políticas al conflicto racial en Cuba. A continuación se ofrece una panorámica sobre el

\footnotetext{
15 Montejo, 2004.

16 Ibarra, 1995: 158-174.

17 Keosha, 2011.

18 Naranjo, 1999. Naranjo y Santamaría, 1999. Núñez Sarmiento, 2002.
} 
movimiento feminista y sufragista durante la República de Cuba, donde la presencia de mujeres negras y mestizas resultó bastante escasa ${ }^{19}$.

\section{SUFRAGISMO Y FEMINISMO SIN MUJERES AFROCUBANAS}

La República Parlamentaria de Cuba se instaura en 1902 y finaliza en 1959. Entre los múltiples conflictos y evoluciones que marcaron la sociedad cubana, hay que rescatar el nuevo protagonismo que, en consonancia con las tendencias existentes en los países occidentales, condicionaron a las mujeres cubanas $^{20}$. Conviene analizar las limitadas medidas políticas que se aprobaron durante esos años de historia republicana para mejorar el estatus político y civil de las mujeres, pero sobre todo interesa entender cómo afectaron a las mujeres afrodescendientes; esto es, a las mujeres clasificadas en aquel período como negras y mestizas.

La asamblea constituyente de 1901 debatió la concesión del voto femenino. Manuel Sanguily se mostró reticente puesto que «no es oportuno, no es momentáneo, no urge, no interesa en estos momentos. Mañana que haya un movimiento feminista, primero entrará la idea en las costumbres y así vendrá á las leyes, y más adelante a la Constitución ${ }^{21}$. La moción presentada por Miguel Gener, Salvador Cisneros Betancourt y José Lacret fue rechazada por 9 votos a favor y 17 en contra. Finalmente, se sancionó el voto masculino para todos aquellos cubanos varones y mayores de 21 años, exceptuando a lisiados, incapaces mentales, activos en servicio militar o inhabilitados judicialmente ${ }^{22}$.

Este nuevo marco legislativo perpetuaba la posición subordinada de las mujeres, les impedía ejercer la plena ciudadanía. Es cierto que pudieron fundar sus propias agrupaciones desde las cuales impulsar campañas y moviliza-

19 Para el caso de las mujeres negras en los Estados Unidos durante el primer tercio del siglo XX, Brown, 2006. Un análisis comparativo de los movimientos feministas en los Estados Unidos después de la II Guerra Mundial, incluyendo a las mujeres afrodescendientes, en Roth, 2004.

20 Para cuestiones generales en torno a la historia del feminismo en época contemporánea: Duby y Perrot, 2000, vol. 4 y 5. Amorós, 2005, vol. 2. Anderson y Zinsser, 2007. Pérez Garzón, 2011. En lo relativo al feminismo y el sufragismo en los Estados Unidos, que sirvió como modelo a los movimientos de mujeres en Cuba: Kraditor, 1981. Julian Spruill, 1993.

21 Diario de Sesiones de la Convención Constituyente de la Isla de Cuba, enero 1901, La Habana, Biblioteca de la Universidad de La Habana (BUH): 283.

22 Diario de Sesiones de la Convención Constituyente de la Isla de Cuba, enero 1901, La Habana, BUH: 284. 
ciones de carácter político. Sin embargo, se les negó el derecho a integrar los partidos tradicionales, así como a votar en los comicios municipales o nacionales. Sin embargo, a partir de 1912 se conformaron las primeras asociaciones femeninas en Cuba. Influidas por el sufragismo estadounidense, las mujeres cubanas desarrollan un estado de conciencia sobre la situación social en que se encontraban. Tras diferentes alianzas y fusiones, se funda el Partido Nacional Sufragista en $1913^{23}$. En parte debido a sus proclamas y actuaciones, el gobierno cubano fue uno de los primeros de Latinoamérica que aprobó las leyes de Patria Potestad, Divorcio y Administración de Bienes ${ }^{24}$.

Las fechas resultan significativas, pues en parte coinciden con la oleada de conquistas logradas por las mujeres en todas las sociedades occidentales al terminar la I Guerra Mundial25. El Club Femenino, instaurado en 1918, desempeñó una labor crucial en la ampliación de frentes de actuación femeninos y la coordinación de las asociaciones femeninas a nivel nacional. A través de La mujer moderna, su revista oficial, solicitó el derecho al sufragio femenino, pero también actuó contra la prostitución, el trabajo infantil, la pena de muerte ${ }^{26}$ o el alcoholismo ${ }^{27}$. En el contexto de los movimientos regeneracionistas de los años veinte, el Club propuso concentrar y armonizar los esfuerzos de las diferentes agrupaciones femeninas con fines políticos. La fundación de la Federación Nacional de Asociaciones Femeninas constituyó la antesala para la convocatoria del I y II Congreso Nacional de Mujeres en 1923 y 1925. Las comisiones que se dieron cita en ambos eventos continuaron debatiendo sobre la estrategia para conseguir que el gobierno actuase en los citados campos, pero también sacó a la luz las primeras divergencias entre las agrupaciones femeninas de distinta ideología.

El movimiento femenino cubano se fragmentó a la altura de 1930, cuando las asociaciones más radicales comenzaron a criticar la especulación política que se estaba realizando con la petición del sufragio. En su opinión, el dictador Gerardo Machado prometía universalizar el voto para ganarse la simpatía del futuro electorado femenino. Como alternativa, propusieron abandonar la vía reformista, dentro de la cual se enclavaba este tipo de reivindicaciones, y continuar por la senda de la rebelión, uniéndose a los obreros y estudiantes

23 Pagés, 2003: 54-58. Lynn Stonner, 2003: 84-87.

24 Pagés, 2003: 60.

25 Para profundizar en la historia de los movimientos feministas en Europa, América y Asia en los años previos e inmediatamente posteriores a la I Guerra Mundial, consultar Glickman, 1984. Sharp y McCrone, 1988. Kingsley, 1990. Cento, Diamond y Marsh, 2000. McMillan, 2000. Ali, 2000. Mead, 2004. Smitley, 2009. Stibbe, 2011.

26 Lamar, 1925a: 25-27; 1925b: 34-35.

27 Lamar, 1926: 27. 
para derrocar el sistema político vigente ${ }^{28}$. En agosto de 1933, la dictadura de Machado fue derrocada. El gobierno de los estudiantes o "Gobierno de los cien días», liderado por Ramón Grau de San Martín y apoyado por el estudiantado universitario, creó las bases para la aprobación por decreto del voto femenino en febrero de 1934. La asamblea constituyente de 1939 lo incluyó en la nueva Carta Magna de $1940^{29}$.

Este podría ser un resumen de las acciones efectuadas por las mujeres cubanas hasta la obtención del derecho al voto. Ahora bien, el movimiento femenino no tuvo un carácter integral. Es decir, no dio cabida en sus asociaciones a todas las clases de mujeres, a pesar de que algunas de estas agrupaciones se describían como interraciales en sus programas fundacionales, como se verá más adelante. El prototipo de mujer cubana feminista o sufragista procedía de la burguesía urbana, había aprobado estudios medios o superiores y era de la «raza» blanca ${ }^{30}$. Estas mujeres cubanas que lideraron la lucha por los derechos femeninos no incorporaron a las mujeres afrodescendientes hasta 1925, cuando Inocencia Valdés, mujer negra sindicada que trabajaba como despalilladora, participó en el II Congreso Nacional de Mujeres ${ }^{31}$ pero en especial a partir del III Congreso Nacional de Mujeres de 1939, cuando adquirieron mayor relevancia.

Como sucedió en los EE.UU., las agrupaciones feministas en Cuba, lideradas y mayoritariamente integradas por mujeres blancas, se mostraron tan inclusivas en la teoría como xenófobas y racistas en la práctica frente a las mujeres afrodescendientes. Esto no quiere decir que las mujeres negras y mestizas careciesen de un pensamiento feminista, sino que se encontraron con diferentes obstáculos para integrarse en todas las esferas sociales, económicas y políticas ${ }^{32}$.

\section{ALFABETIZACIÓN Y FORMACIÓN PROFESIONAL}

En el censo de 1907, se establece que el $57 \%$ de la ciudadanía cubana sabía leer, frente al $78 \%$ en $1953^{33}$. Por sexo, a comienzos de la República,

28 Lynn Stonner, 2003: 15ss.

29 En lo relativo a la asamblea constituyente, Stonner, 2003: 124-151. Para contextualizar los siete años que median entre la caída de Gerardo Machado y la aprobación de la Constitución de 1940, O’Brien, 1999: 205-251. Whitney, 2010: 141-301.

30 Stonner, 2003: 113-124.

31 Pagés, 2003: 70.

32 Para los impedimentos que experimentaron las mujeres afroamericanas en los Estados Unidos, Roth, 2004: 76-79.

33 Oficina Nacional de Estadísticas, 1996: 200. 
tenía esta capacidad el 55,02\% de las mujeres, frente al 56,03\% de los hombres. Los porcentajes se invirtieron en 1953: 79\% de mujeres, $75 \%$ de hombres. Ahora bien, si se ahonda en el análisis, se descubren diferencias entre las mujeres blancas, negras y mestizas.

La construcción de colegios antes y durante la primera ocupación norteamericana (1899-1902), así como la aprobación de la primera Primera Ley Escolar en 1909 favorecieron que los índices de alfabetización entre los niños $\mathrm{y}$ adolescentes aumentasen ${ }^{34}$. En consecuencia, se redujeron las diferencias educacionales entre «razas» desde la base, lo que produjo resultados en el largo plazo. Dos años antes, en 1907, el 70,2\% de las chicas entre los 10 y 19 años, clasificadas como «de color», sabían leer, frente al 70,02\% de las blancas en el mismo tramo de edad (véase gráfico 1).

\section{Gráfico 1. Comparación PORCENTUAL DE ADOLESCENTES CUBANAS QUE SABÍAN LEER (10-19 AÑOS)}

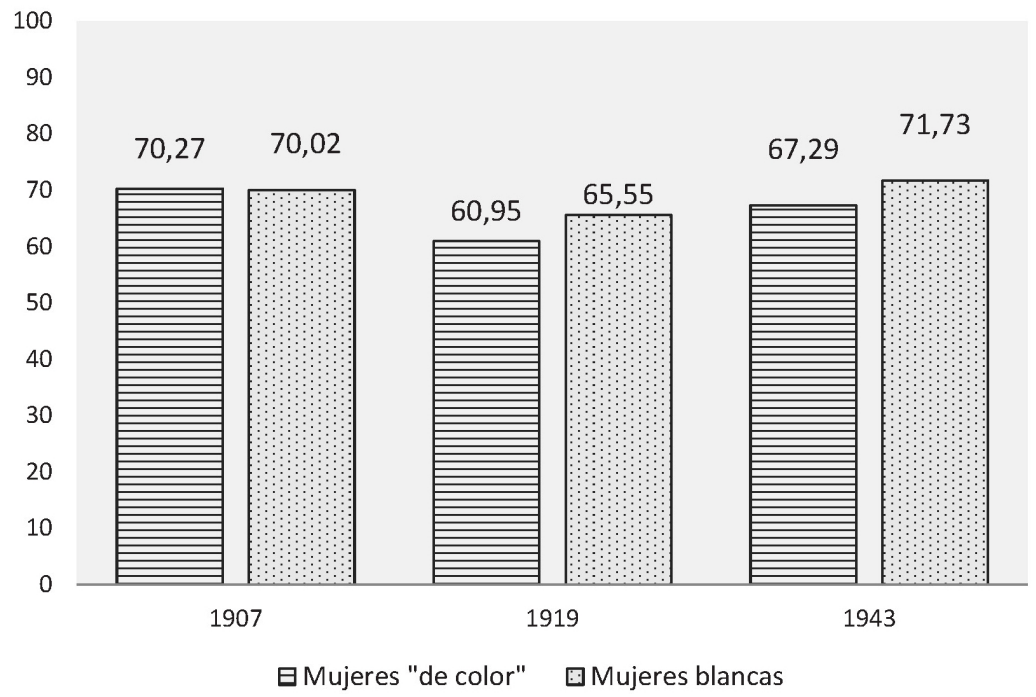

Fuentes: censos de 1907, 1919 y 1943. Elaboración propia.

34 «El período de la ocupación norteamericana en Cuba, iniciado en 1898, favoreció los avances en el sistema de enseñanza, y en el segundo semestre de 1890 el número de escuelas primarias ascendía a más de 3.300 -10 veces más que las disponibles el año anterior-. Los escolares asistentes a clases sobrepasaron los 135.000; se incrementaron los textos, que eran traducciones de libros norteamericanos; se introdujeron nuevas asignaturas en los planes de estudios y se formaron gran número de maestros», en Pichardo, 1986: 119. 
Aunque en términos porcentuales había decrecido tres puntos, entre el censo de 1907 y 1943 se triplicó el número total de niñas «de color» que sabían leer (véase gráfico 2). La documentación no permite conocer cuántas sabían escribir.

\section{Gráfico 2. Cifras totales de adolescentes cubanas que sabían LeER (10-19 AÑOS) \\ 目 Mujeres "de color" 圈 Mujeres blancas}

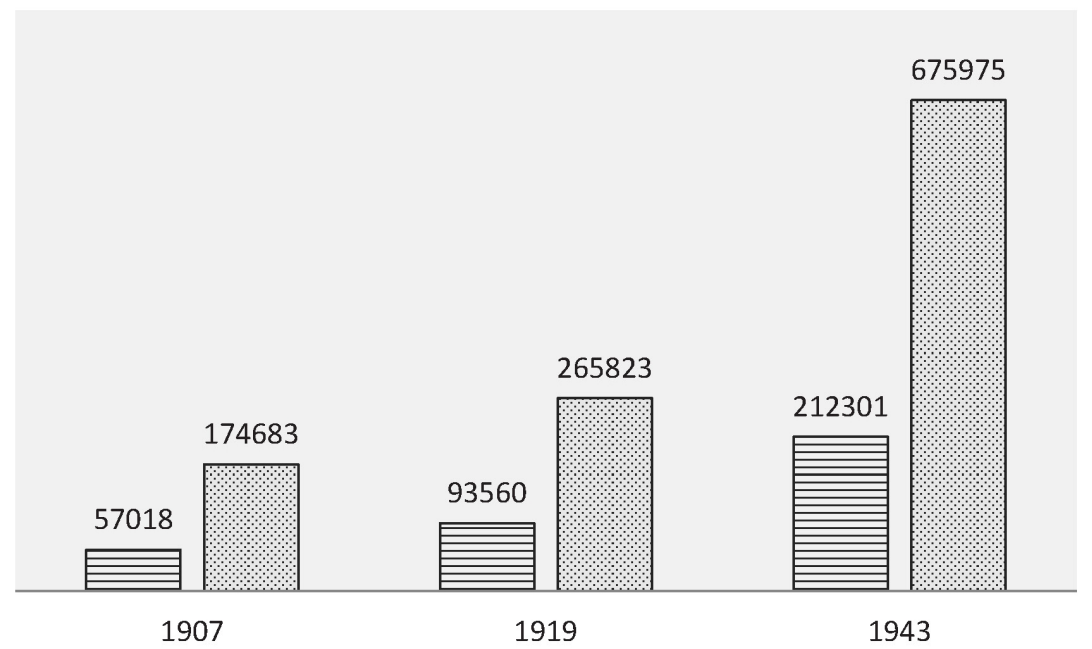

Fuentes: censos de 1907, 1919 y 1943. Elaboración propia.

Cuando se amplían los tramos de edad analizados, se descubren mayores diferencias. A la altura de 1907, solo el $34,2 \%$ de las mujeres «de color» mayores de 20 años era capaz de leer, frente al 58,2\% de las mujeres blancas, cubanas y extranjeras. Se debe recordar que cuando se confeccionaron aquellas estadísticas, solamente habían transcurrido 19 años desde la abolición legislativa de la esclavitud y 10 años desde la independencia frente a España. Sin embargo, en 1943, la diferencia porcentual de mujeres alfabetizadas blancas y afrocubanas era del 3,5\%: 74,5\%, frente al 71\% (véase gráfico 3). Esto puede explicarse como consecuencia del progreso acumulado en la alfabetización de las generaciones formadas bajo la instrucción básica obligatoria instaurada en el período republicano, como se ha apuntado previamente. 
Gráfico 3. Comparación PORCENTUAL DE CUBANAS QUE SABÍAN LEER (MAYORES DE 20 AÑOS)

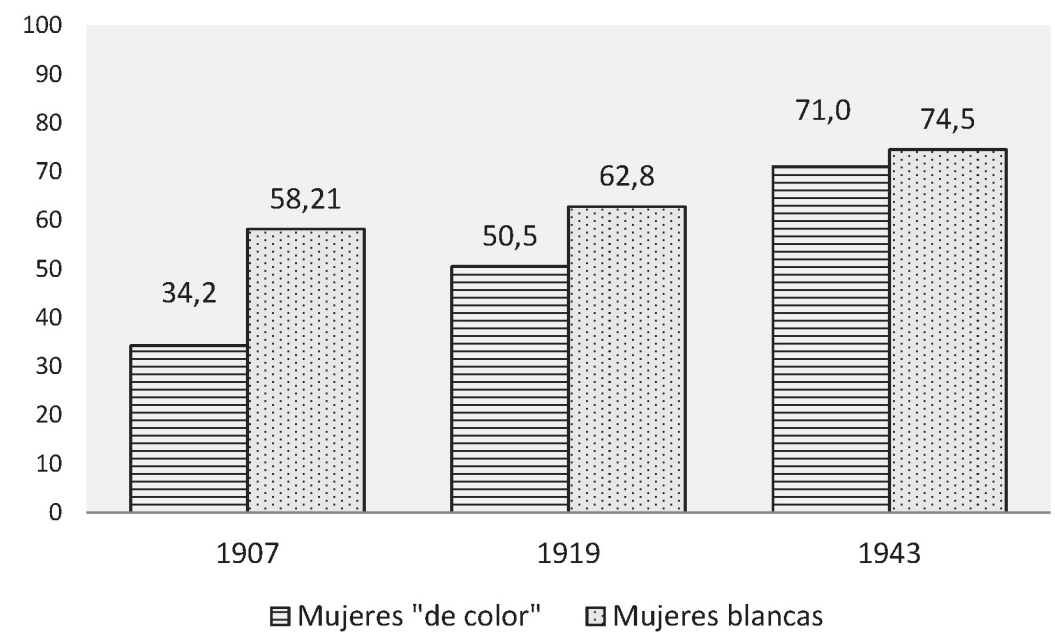

Fuentes: censos de 1907, 1919 y 1943. Elaboración propia.

Las diferencias de género en lo relativo a la alfabetización de la población se redujeron con el transcurso de la república de $\mathrm{Cuba}^{35}$. Si en 1907 el 41,9\% de las mujeres «de color» sabía leer, frente al 44,6\% de los hombres negros y mestizos, en 1943 se había invertido la situación, 69,9\% frente a 65,1\% (véase gráfico 4).

Este cambio de paradigma podría atender a dos aspectos. Primero, porque en el ámbito rural había menos escuelas y los hombres «de color» las abandonaban antes para empezar a trabajar. La población femenina «de color» emigraba en mayor medida a la ciudad en busca de oficios que pudieran ser desempeñados por mujeres en el ámbito de la industria ${ }^{36}$. En el contexto urbano, probablemente tuvieron un mayor contacto con los medios de comunicación y las instituciones educativas, lo que a la larga pudo mejorar su formación frente a los hombres de su «raza». Sin embargo, en términos porcentuales, las mujeres «de color» no equipararon su índice de alfabetización con los hombres «de color», ni con la población blanca hasta el final del período republicano (véase gráfico 5).

35 Unas notas al respecto en Huerta, 1990. Nascimiento, 1995. González y Reyes, 2009: $15-17$.

36 Ibarra Cuesta, 1995, Anexos y gráfico 29. 
Gráfico 4. Porcentaje de población total «DE COLOR» AlFabetizada, POR SEXO

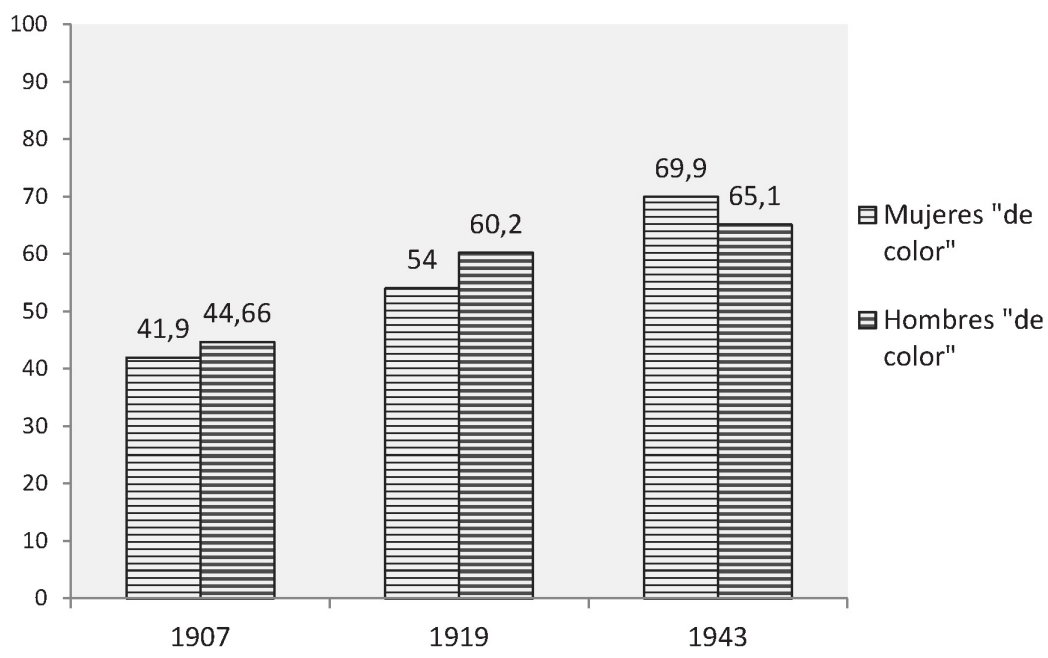

Fuentes: censos de 1907, 1919 y 1943. Elaboración propia.

GrÁfico 5. COMPARACiÓn PORCENTUAL de POBlaCión ALFABETIZADA, SEGÚN SEXO Y «RAZA». FUENTES: CENSOS DE 1907, 1919 Y 1943

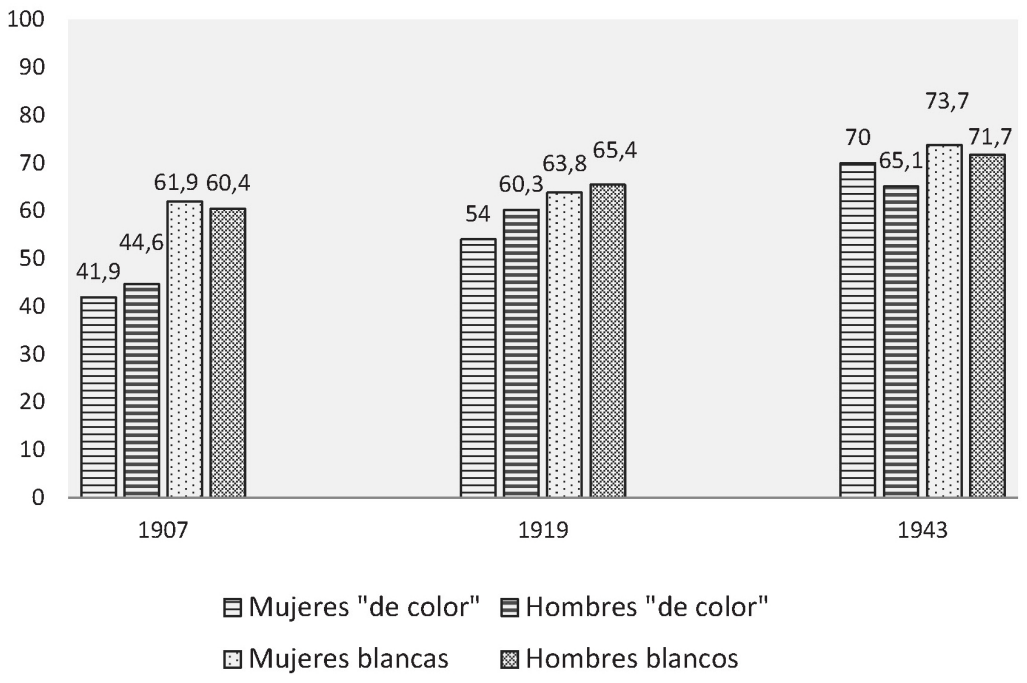

Fuente: elaboración propia. 
Por otro lado, el gasto en educación se elevó progresivamente desde el 2,6 al 3,2\% del PIB entre 1940 y $1950^{37}$. Si bien estas cifras son un indicador de la mayor preocupación política por la formación de la ciudadanía, esto no significa, necesariamente, un incremento de las inversiones dedicadas a la formación de la comunidad afrocubana.

En el Censo de 1919 se ofrece un registro de asistencia escolar. Los datos permiten descubrir que las jóvenes afrocubanas asistían a clase en los mismo términos que las alumnas blancas. Al contrario de lo que pueda parecer, el promedio de absentismo escolar era similar entre las estudiantes de ambas «razas» de 10 años en adelante: 18,18\% de las estudiantes blancas, frente al $18,24 \%$ de las negras y mestizas. Si se ajusta la lente sobre algunos tramos de edad pueden percibirse diferencias acusadas. Entre los 10 y 17 años apenas hay variaciones porcentuales. Sin embargo, a partir de esa edad, el 43,9\% de las alumnas «de color» de 18 años y mayores asisten más de cuatro meses al año a clase, frente al 30,4\% de las alumnas blancas (véase gráficos 6 y 7).

GrÁfico 6. Asistencia escolar femenina, SEgún la «RAZA». Menos de CUatro Meses al aÑo

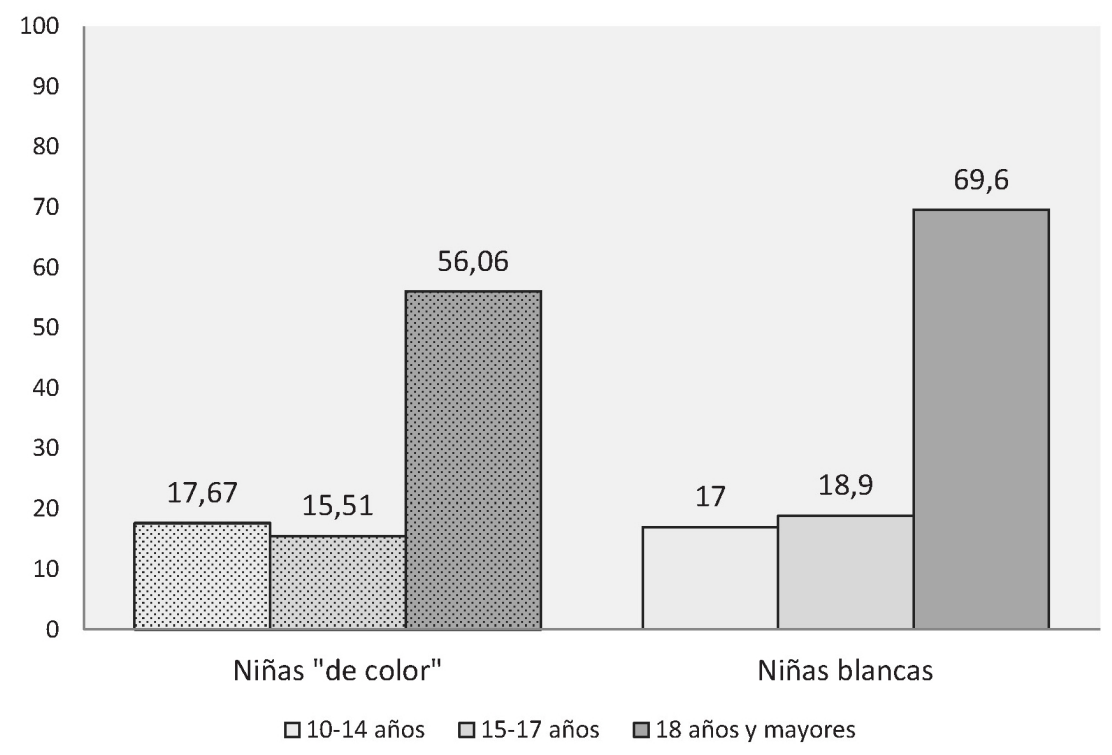

Fuente: censo 1919. Elaboración propia.

37 Santamaría, 2009: 120. 


\section{GrÁFico 7. AsistenCia ESCOLAR FEMENINA, SEGÚN LA «RAZA». Más de CUATro Meses al AÑo}

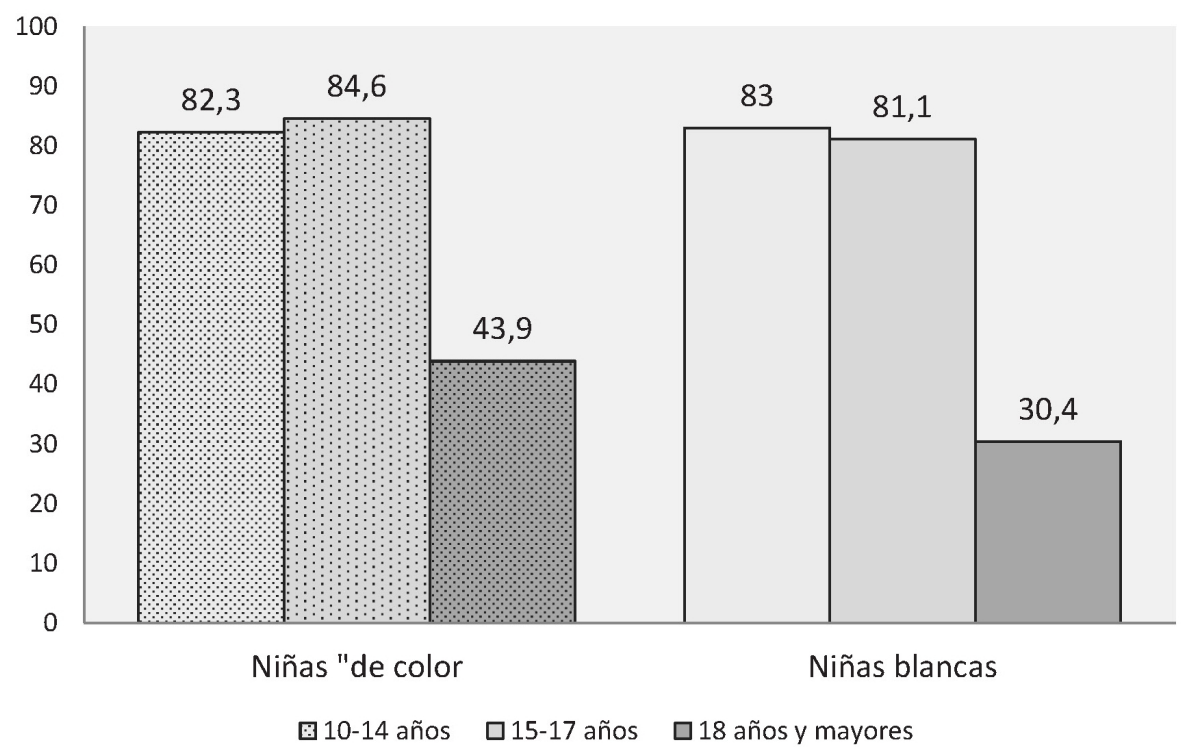

Fuente: censo de 1919. Elaboración propia.

Esto puede deberse a varias razones. Por un lado, quizás las estudiantes blancas eran contratadas a edad más temprana que las «de color» o dejaban sus estudios para ayudar en negocios de carácter familiar. También es probable que las alumnas blancas procedentes de sectores sociales mejor acomodados abandonasen la educación reglada, bien para recibir formación particular en el hogar, bien porque se considerase que las mujeres solo necesitaban saber atender las labores del hogar, e incluso quizás para contaer matrimonio.

Las mujeres de color tal vez asistían con mayor frecuencia al colegio como una estrategia familiar de ascensión social por medio de la educación. Sin embargo, la población afrocubana solo podía recibir docencia por parte del profesorado afrodescendiente, que por, además, era minoritario. A ello hay que añadirle cómo afectaría a este sector poblacional que a lo largo de la República de Cuba la educación recayese progresivamente en manos privadas. Entre 1900 y 1930, el 87\% de las escuelas de primaria pertenecía al sistema público, lo que facilitaba el acceso a la instrucción básica obligatoria. Sin embargo, no se puede decir lo mismo de la educación secunda- 
ria. En 1920, solamente el 13\% de escuelas secundarias tenían carácter público ${ }^{38}$.

Con el paso de los años, aumentó la tendencia a contratar personas jóvenes, mujeres en su mayoría, para trabajar en la industria y los servicios domésticos. De hecho, en palabras de Jorge Ibarra «en 1899 el grupo de edades de 15 a 24 años abarcaba un $21,7 \%$ del total de trabajadoras y en 1953 el mismo había aumentado a un $36,3 \% »^{39}$. Como se verá a continuación, a mediados del siglo XX, la mayoría de mujeres cubanas, tanto blancas como afrodescendientes, continuaban siendo contratadas en oficios de carácter manual que requerían baja cualificación. La necesidad de mano de obra barata para el servicio doméstico y los cuidados del hogar por parte de ciertos sectores sociales y el encarecimiento del nivel de vida para los grupos peor remunerados, quizás empujó a algunas adolescentes negras y mestizas a abandonar sus estudios para integrar el mercado laboral. Otras tuvieron la oportunidad de continuarlos, con la intención de llegar a la universidad.

La segregación de las mujeres afrocubanas se descubre aún más drástica cuando se examinan los datos relativos a la educación superior. En términos porcentuales, las mujeres de ambos grupos se licenciaban en carreras relacionadas con la enseñanza o los cuidados médicos, proyecciones públicas de los roles tradicionales que desempeñaban en el hogar. En 1943, el 46\% de las mujeres «de color» se licenciaban como maestras normalistas y el $15,6 \%$ como comadronas, mientras que el $18 \%$ había conseguido el bachillerato. De igual manera, el $44,5 \%$ y el $22,9 \%$ de las mujeres blancas se graduaron como normalistas y bachilleres, respectivamente (véase gráfico 8).

En términos absolutos, a la altura de 1943, se habían licenciado 22.923 mujeres blancas, por tan solo 3.849 negras y mestizas (véase gráfico 9). Es decir, una relación de seis a una. La proporción de mujeres licenciadas frente al total del estudiantado, masculino y femenino, y teniendo en cuenta el factor racial, resultaba casi inapreciable: las mujeres blancas constituían el 1,35\% del total de licenciados y las mujeres afrocubanas el $0,67 \%{ }^{40}$. Además, en ninguna carrera había más mujeres negras o mestizas que blancas, excepto en la licenciatura de comadronas. Por añadido, solo se encuentran más de cien mujeres de color en todo el país tituladas en bachillerato y licenciadas como maestras, comadronas, farmacéuticas y doctoras en pedagogía. Las mujeres blancas superaban las cien licenciadas en estas carreras, pero también en otras

38 De la Fuente, 2000: 206.

39 Ibarra Cuesta, 1995: 162.

4022.923 licenciadas de un total de 1.697 .527 mujeres blancas; 3.849 licenciadas para un total de 582.246 mujeres de «de color», Censo de 1943 de la república de Cuba, 1945: 756. 
GrÁfico 8. Distribución PORCENTUAL DE MUJERES CON ESTUDIOS SUPERIORES, SEGÚN TÍTULOS Y «RAZA»

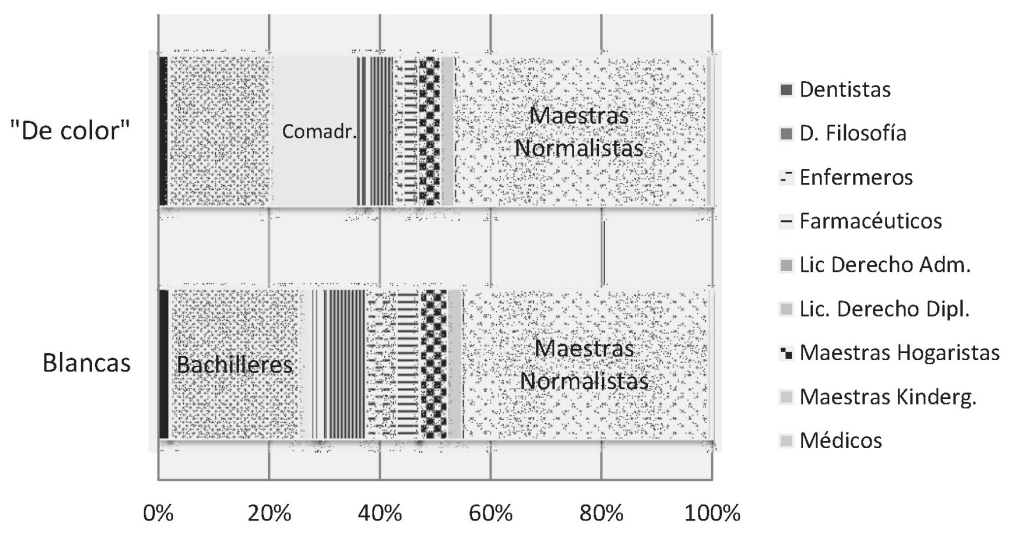

Fuente: censo de 1943. Elaboración propia.

Gráfico 9. Cifras totales de mujeres CON estudios Superiores, SEGún título $\mathrm{Y}$ «RAZA»

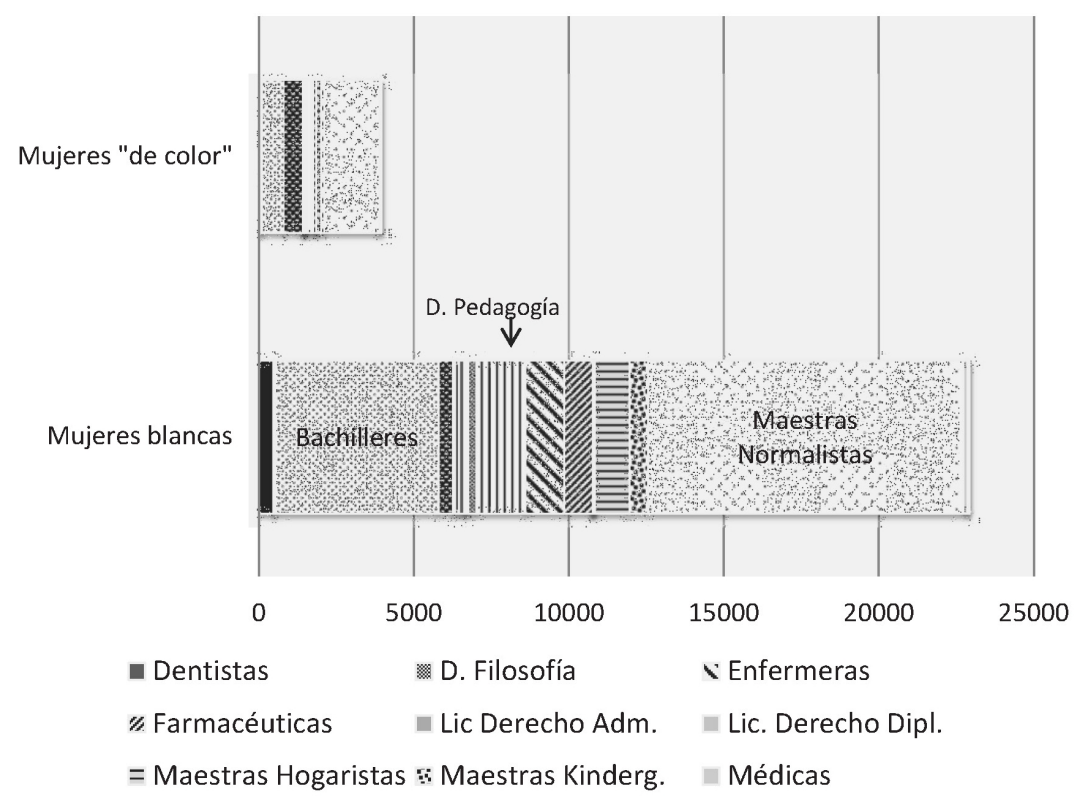

Fuente: censo de 1907, 1919 y 1943. Elaboración propia. 
como humanidades y ciencias médicas: abogacía, contaduría, odontología, filosofía, enfermería y medicina (véase gráfico 10).

\section{Gráfico 10. Mujeres afrocubanas en CARRERAs CON MÁs DE CIEN MUJeres BLANCAS LICENCIADAS}

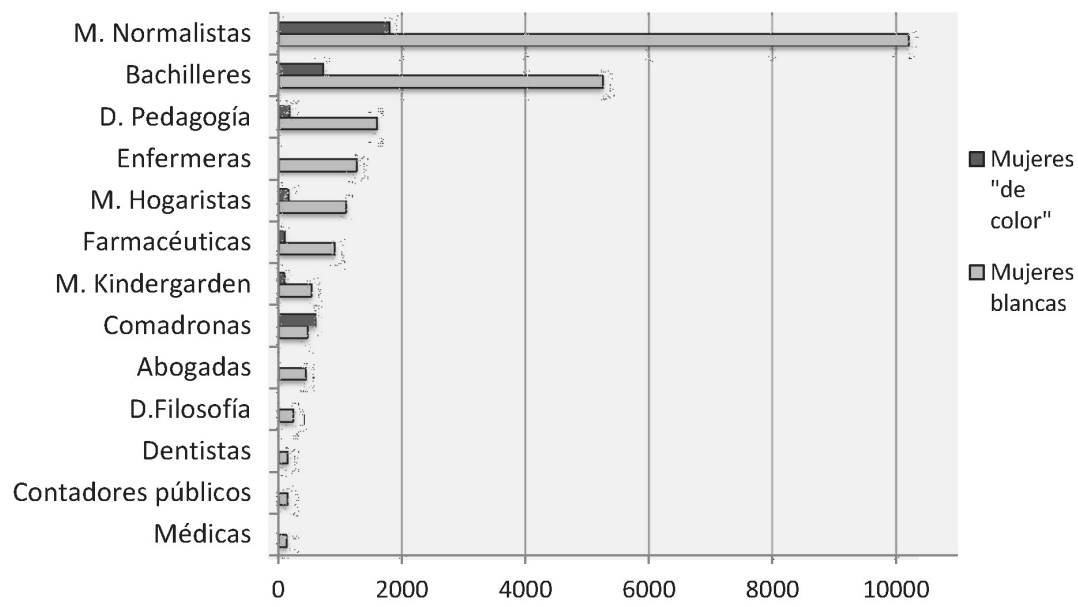

Fuente: censo de 1943. Elaboración propia.

La progresiva tecnificación de las mujeres blancas se aprecia en aquellas carreras donde no encontramos ninguna licenciada negra o mestiza. Esto es, ingenierías, agrimensura o carreras vinculadas al comercio (véase gráfico 11).

Estos resultados pueden venir dados por condicionantes sociales y limitaciones salariales. Por un lado, los ingresos medios de la población afrodescendiente respecto a la población blanca eran inferiores cuando desempeñaban oficios similares ${ }^{41}$. Esto impedía que se conformase un sector poblacional intermedio entre los afrodescendientes con capacidad para invertir sus excedentes gananciales en la educación superior, que en aquel momento no era gratuita en $\mathrm{Cuba}^{42}$. De esta forma, se puede aventurar que las mujeres «de color» licenciadas a la altura de 1943 pertenecían a la incipiente burguesía negra y mestiza, que a su vez alumbró las primeras asociaciones políticas de negros y mestizos como el Lyceum de La Habana y el Club de Atenas, don-

${ }^{41}$ Censos de población, viviendas y electoral, 1953: 1098-1112.

42 González González y Reyes Velázquez, 2010: 13-35. 
Gráfico 11. Cifra total de mujeres blancas licenciadas en CARreras donde NO HABÍA MUJERES «DE COLOR»

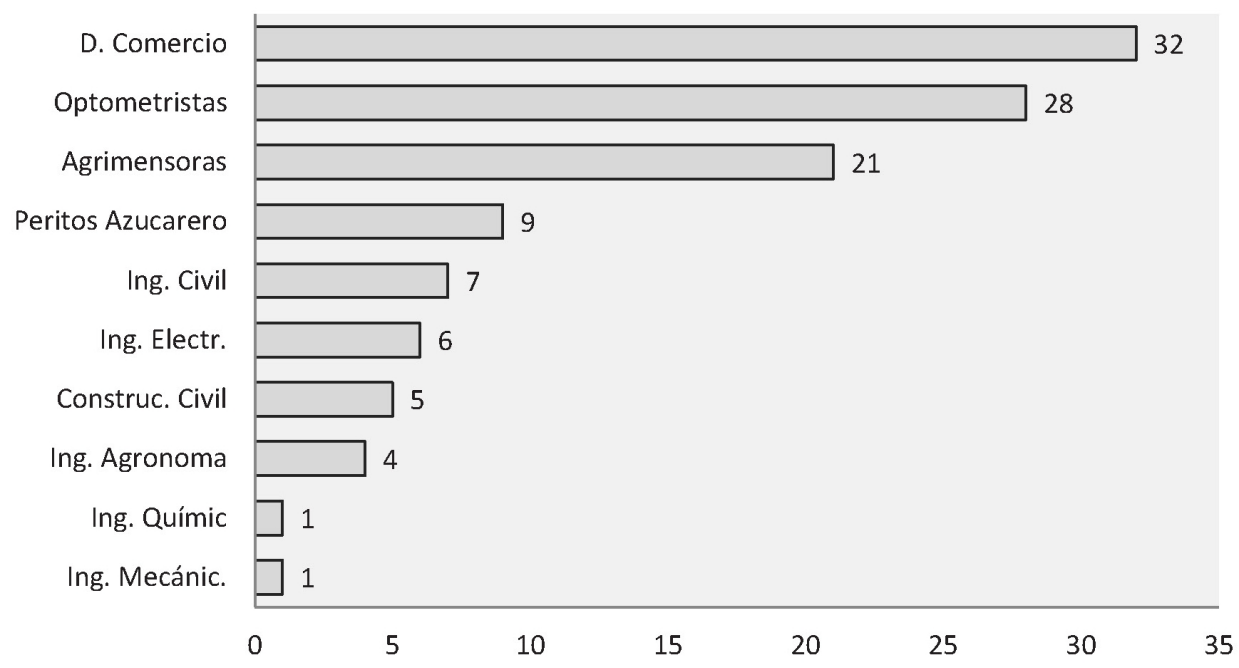

Fuente: censo de 1943. Elaboración propia.

de también participaron algunas mujeres, pero bajo los tradicionales roles de acompañante o «ángel del hogar» ${ }^{43}$. Para comprender la dificultad que suponía acceder a la formación superior, se debe puntualizar que la Universidad de La Habana admitía a un número muy limitado de estudiantes: 5.000 en 1930, 15.000 en 1945. La competitividad académica, junto a otros factores, incrementó el precio de la matrícula universitaria. Las becas para estudios superiores no paliaban la brecha económica entre la población blanca y afrocubana. De hecho, a la altura de 1925, los alumnos negros y mulatos constituían apenas el $11 \%$ de todos los estudiantes universitarios ${ }^{44}$. En 1936, el proyecto de ley docente presentado por Ramón Vasconcelos al Senado de Cuba establecía que se concedería un número limitado de becas que nunca superaría el $20 \%$ del total de matrículas ofertadas ${ }^{45}$.

\footnotetext{
43 Pignot, 2010: 847 (nota al pie).

44 De la Fuente, 2000: 211.

45 Pichardo, 1986: 116.
} 
LA INCORPORACIÓN LABORAL DE LAS AFROCUBANAS. ÁMBITO DE SEGREGACIÓN RACIAL

Uno de los índices más seguros para medir la expansión económica de los países lo constituye la incorporación femenina al trabajo. Entre 1899 y 1943, el porcentaje de mujeres que se dedicaban a actividades lucrativas pasó del $8,79 \%$ al $10,22 \%{ }^{46}$. Sin embargo, entre 1907 y 1943 su presencia entre la fuerza laboral cubana en su conjunto, masculina y femenina, decreció desde el 9,3\% al 8,25\%. Es decir, el mercado laboral en Cuba se masculinizó a lo largo de la república de Cuba.

Aun con ello, las mujeres blancas aumentaron su presencia en términos absolutos y porcentuales. Sin embargo, en el mismo lapso de tiempo, las mujeres «de color» disminuyeron su presencia en todos los aspectos. En 1907 había 47.612 mujeres afrocubanas empleadas, mientras en 1943 habían disminuido hasta las 44.220 (véase gráfico 12).

\section{Gráfico 12. Cifras totales del empleo femenino en Cuba durante LA REPÚBLICA, POR «RAZA»}

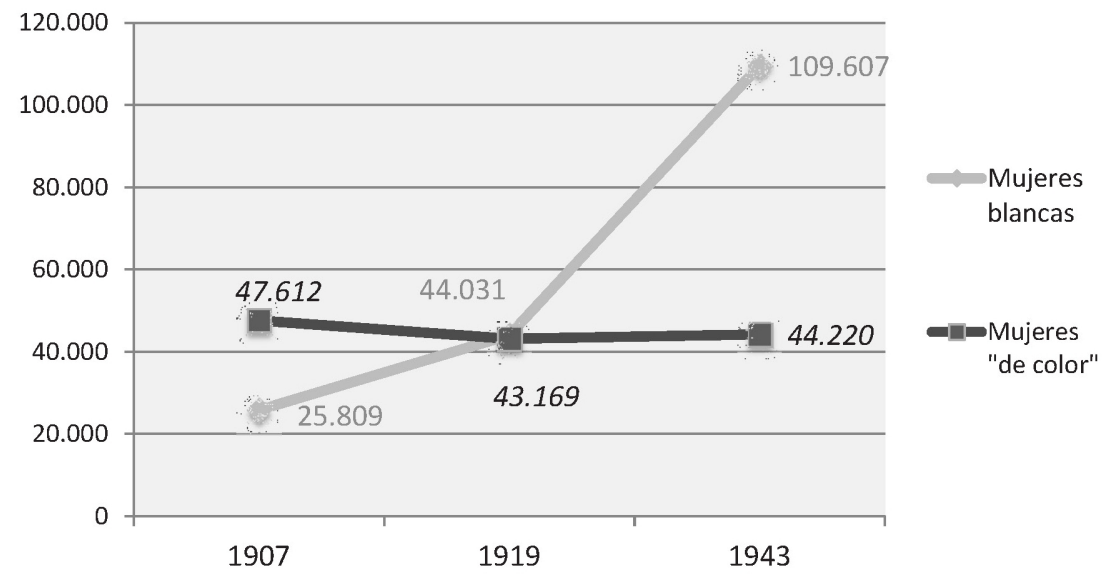

Fuentes: censos de 1907, 1919 y 1943. Elaboración propia.

En términos porcentuales, su fuerza laboral en el sector femenino disminuyó del 64\% al 28\% (véase gráfico 13), mientras cayó del 6,04\% al 2,3\% si

46 Ibarra, 1995: 159. 
se compara con toda la población empleada a nivel nacional (véase gráfico 14).

\section{Gráfico 13. Distribución porcentual del empleo femenino en Cuba} DURANTE LA REPÚBLICA, SEGÚN LA «RAZA»

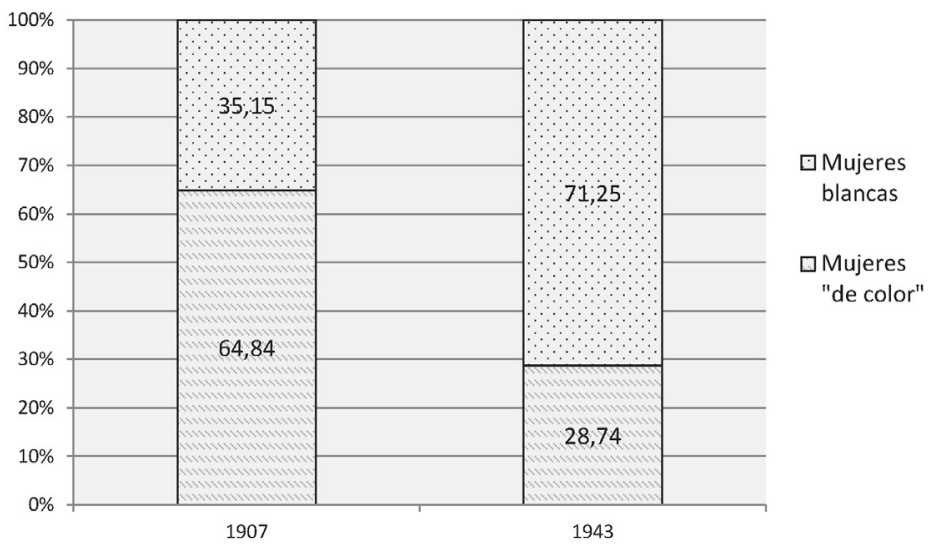

Fuentes: censos de 1907 y 1943. Elaboración propia.

Gráfico 14. Evolución porcentual del empleo en Cuba, SEGÚN SEXO Y «RAZA».

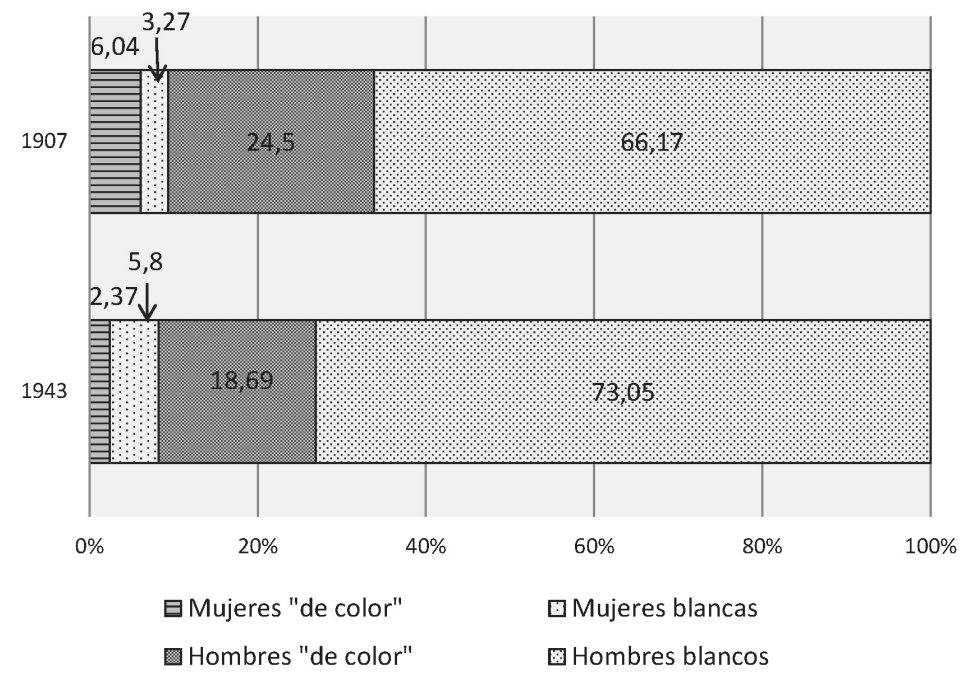

Fuentes: censos de 1907 y 1943. Elaboración propia. 
Dicho de otra forma, mientras la fuerza laboral total de mujeres afrocubanas no solo se estancó sino que disminuyó levemente, las mujeres blancas con empleo remunerado se cuadruplicaron en menos de cuarenta años. Para comparar, si se examina el caso de los hombres afrocubanos respecto a los hombres blancos, en 1907 había 192.883 trabajadores negros y mestizos, frente a los 348.582 de 1943. En términos porcentuales, disminuyó su presencia entre la mano de obra masculina desde el $27 \%$ al $20 \%$, y cayó del $24 \%$ al $18 \%$ respecto al total de personas empleadas (véanse gráficos 14 y 15).

Gráfico. 15. Evolución del empleo total en Cuba duRANTE la RepúBlica, SEGÚN SEXO Y «RAZA»

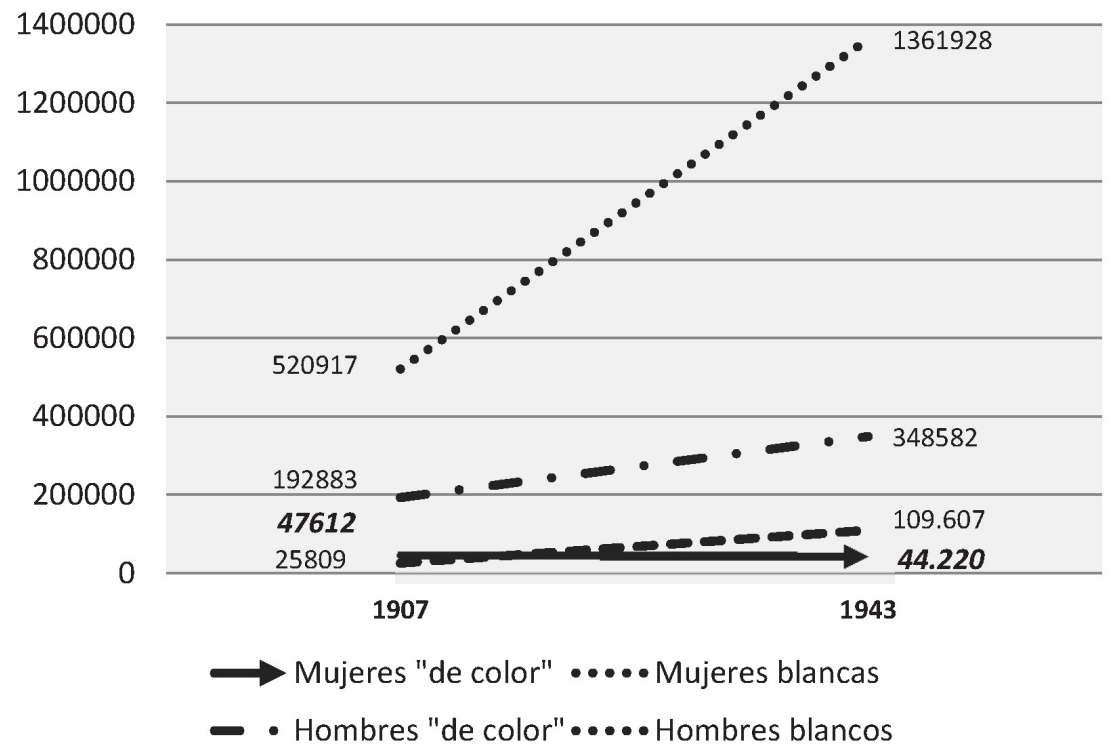

Fuentes: censos de 1907 y 1943. Elaboración propia.

Como se observa, la población afrocubana en su conjunto perdió relevancia en el terreno laboral a lo largo de la República. Sin embargo, mientras los varones al menos crecían en términos absolutos, las mujeres decrecieron en todos los aspectos. Muy probablemente, el mayor número de mujeres blancas con posibilidad de realizar estudios medios condicionó el acceso de las mujeres afrodescendientes a puestos laborales antes restringidos al sexo femenino. Sin embargo, resulta llamativo que las mujeres blancas también pasaron a 
constituir mayoría en aquellos trabajos donde a comienzos de siglo predominaban las mujeres negras y mestizas. Por ejemplo, en 1907 se constatan 15.765 criadas, 7680 costureras y modistas y 2143 agricultoras «de color», por 7.613, 4116 y 967 mujeres blancas. En el censo de 1943 se registraron 17697 criadas, 3857 costureras y modistas, y 2545 agricultoras «de color», frente a 15442, 10623 y 8245 mujeres blancas en los mismos empleos (véase gráfico 16). A continuación se pasará a examinar este proceso con mayor detalle.

GrÁfico 16. Total de MUJeres EMPLEAdAS EN OFICIOS DE BAJA CUALIFICACIÓN, POR «RAZA»

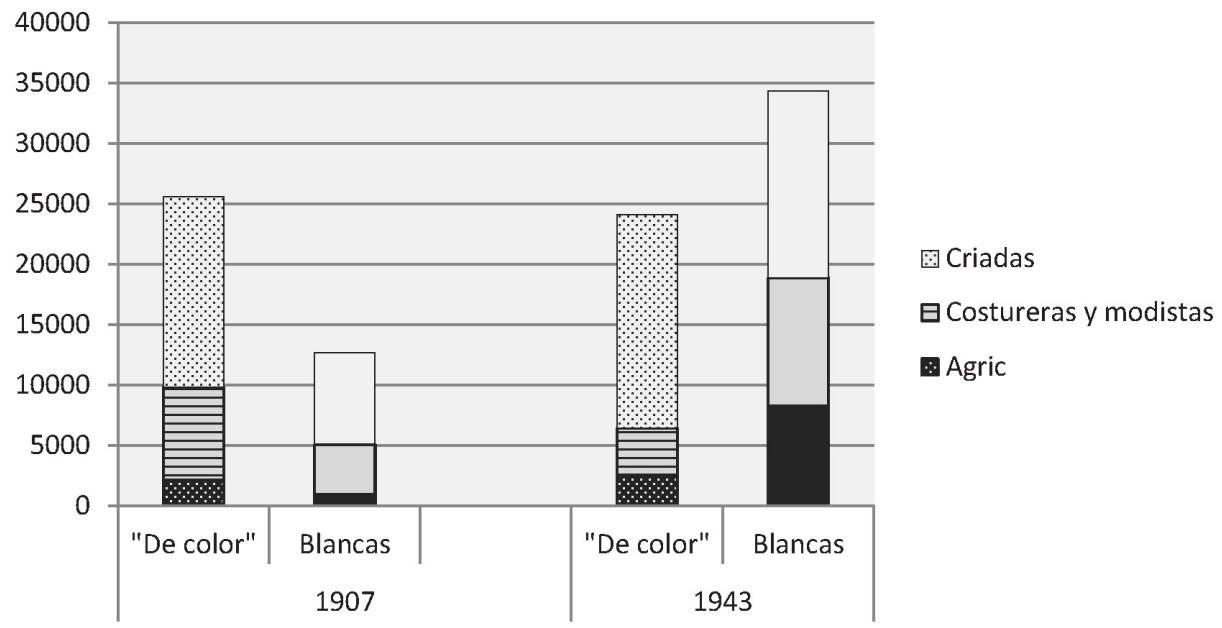

Fuentes: censos de 1907 y 1943. Elaboración propia.

Abolida la esclavitud, la población afrodescendiente, sobre todo las mujeres, emigró progresivamente a las ciudades. Allí desempeñaron de forma remunerada labores que ya habían realizado bajo el antiguo sistema esclavista y que venían a ser, al mismo tiempo, expresión pública de las tareas que desarrollaban en el ámbito privado del hogar. Como se apuntaba, en 1907 había 47.612 mujeres afrocubanas trabajando por 25.809 mujeres blancas. Si bien en un principio había un mayor número mujeres negras y mestizas en el mercado laboral, estaban empleadas en menor variedad de oficios. E1 90\% de las mujeres negras y mestizas recibían remuneración como lavanderas, criadas, costureras o agricultoras (véase gráfico 17). 
Gráfico 17. COMParación PORCENTUAL DE EMPleOS FEMENINOS, SEGÚN «RAZA» (EN OFICIOS CON MÁS DE 50 TRABAJADORAS A NIVEL NACIONAL)

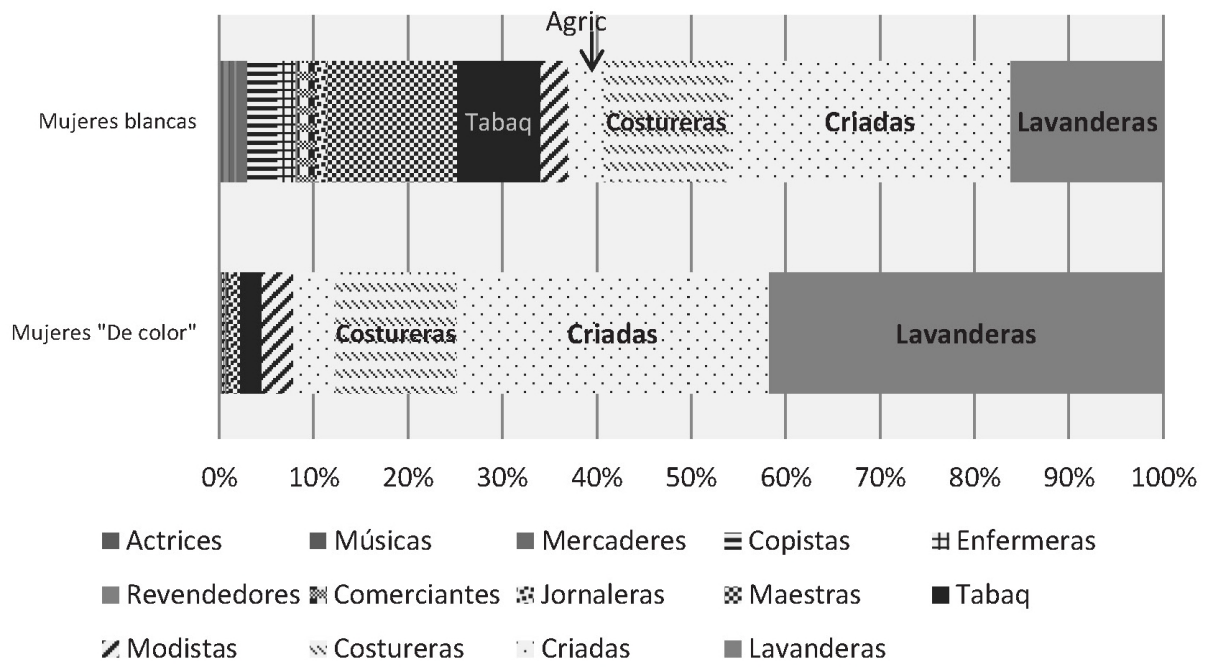

Fuente: censo de 1907. Elaboración propia.

Las mujeres blancas también realizaban estas labores, pero además constituían mayoría entre las modistas, tabaqueras, maestras y secretarias. Estos dos últimos oficios apuntaban una tendencia entre las mujeres blancas: la progresiva incorporación a sectores laborales de trabajo no manual (véase gráfico 18).

Entre el censo de 1907 y el de 1919 ocurrieron algunos hechos destacados en la república de Cuba. En los años previos a la I Guerra Mundial y al ciclo alcista en el mercado azucarero, el Partido de los Independientes de Color se erigió como el vocero de la marginación social que estaba experimentando la población afrodescendiente. Sin embargo, no llevó a cabo ninguna iniciativa para mejorar la situación de las mujeres negras y mestizas en lo relativo a las condiciones laborales ${ }^{47}$. Los primeros partidos feministas y sufragistas, entre 1913 y 1918, se describieron como agrupaciones orientadas a la promoción de todas las mujeres, sin discriminación, pero tampoco tuvieron la capacidad o la iniciativa de actuar en favor de las mujeres afrodescendientes ${ }^{48}$.

\footnotetext{
47 Previsión, 15 octubre 1908: 3.

48 El feminista cubano, 26 diciembre 1912.
} 
GrÁFICO 18. TOTAL DE MUJERES EMPLEADAS, SEGÚN OFICIOS Y «RAZA» (EN OFICIOS CON AL MENOS 50 TRABAJADORAS A NIVEL NACIONAL)

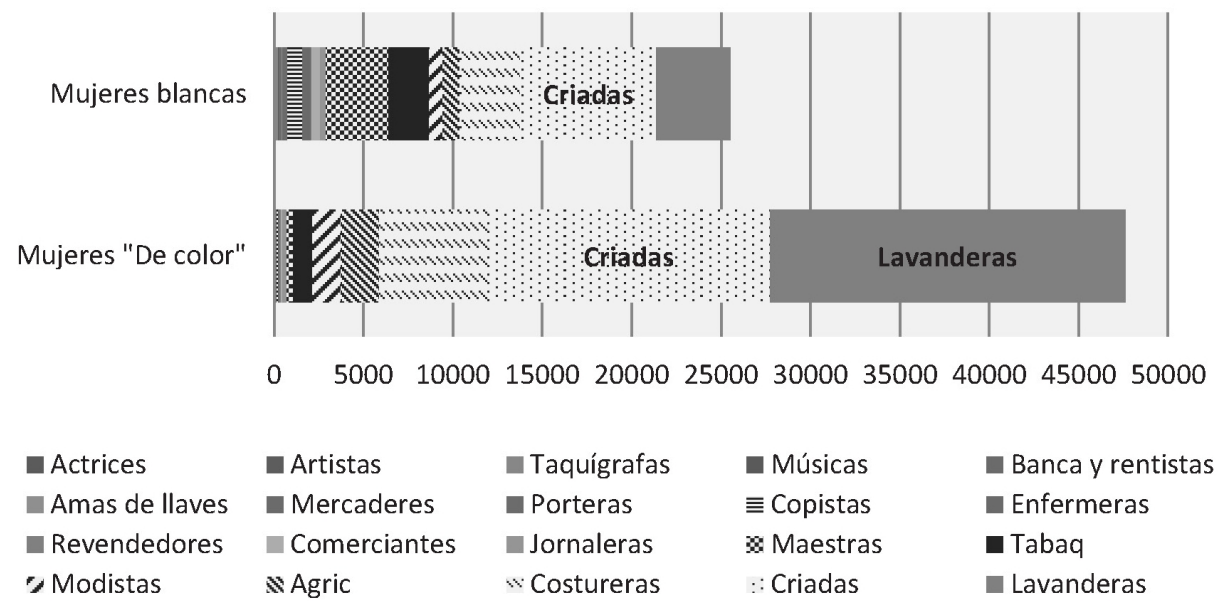

Fuente: censo de 1907. Elaboración propia.

Como refleja el censo de 1919, el número de mujeres afrodescendientes empleadas había disminuido, mientras las mujeres blancas se habían incorporado de forma masiva a la fuerza de trabajo: 43.169 mujeres negras y mestizas, por 44.031 mujeres blancas. Casi el 90\% de mujeres afrocubanas seguía ejerciendo como criada, lavandera o agricultora La novedad es que en poco más de diez años respecto al registro anterior, en todo el territorio nacional había al menos cien mujeres afrodescendientes desempeñando oficios como escoberas, toldistas y funcionarias (véanse gráfico 12 y 19).

Los dos primeros están más vinculados al mundo urbano, pero la incorporación a empleos estatales se reafirma en los datos de 1943, cuando se quintuplicó el número de mujeres afrocubanas que ingresaron al sector público. Sin embargo, mientras las mujeres afrocubanas se abrían paso en la industria urbana, las mujeres blancas lo hacían en el sector servicios. Entre 1907 y 1919, las mujeres blancas fueron contratadas en la hostelería, las comunicaciones y las finanzas. Por ejemplo, encontramos 681 oficiales de banco, 341 hosteleras y 424 telégrafas mujeres blancas, por 56, 25 y 34 mujeres «de color» (véase gráfico 20).

En 1943, el número total de mujeres empleadas en Cuba ascendía a 153.827. Las mujeres blancas constituían el $71,25 \%$ de la fuerza laboral femenina con 
GRÁfico 19. DistribuCiÓN PORCENTUAL DE EMPLEOS FEMENINOS, SEGÚN «RAZA» (EN OFICIOS CON AL MENOS 100 TRABAJADORAS A NIVEL NACIONAL)

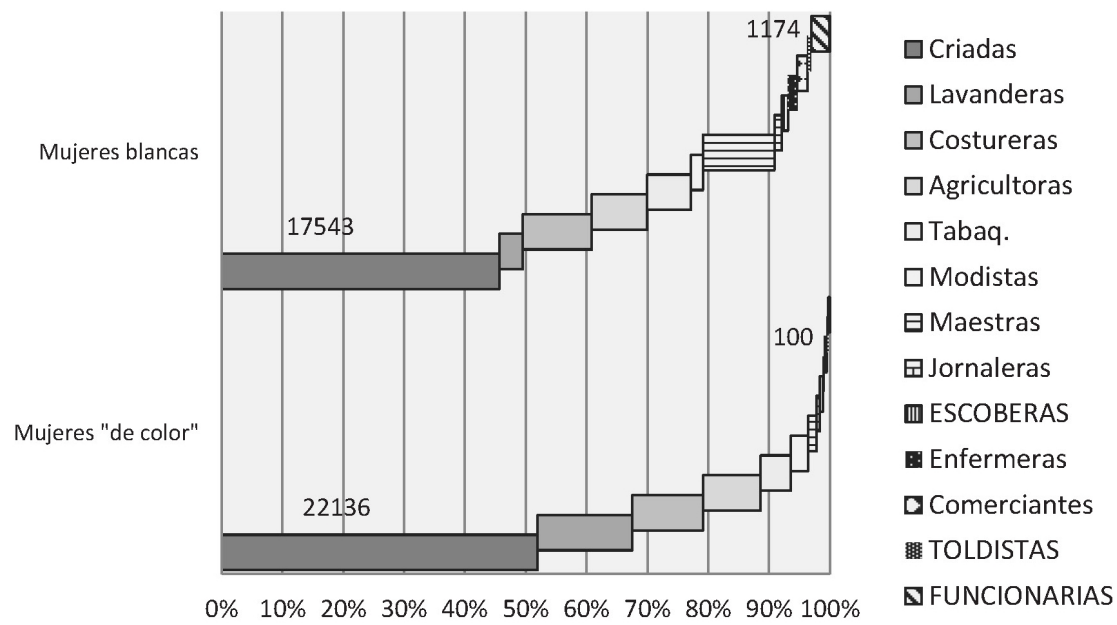

Fuente: censo 1919. Elaboración propia.

GRÁFico 20. EMPLEOS DONDE LAS MUJERES NEGRAS NO SUPERAN LAS 100 PERSONAS EN TODO EL TERRITORIO NACIONAL, EN COMPARACIÓN CON LAS MUJERES BLANCAS (EN MAYÚSCULAS LOS NUEVOS OFICIOS DONDE LAS MUJERES NO TENÍAN PRESENCIA O NO ESTABAN REGISTRADOS EN EL CENSO ANTERIOR, 1907).

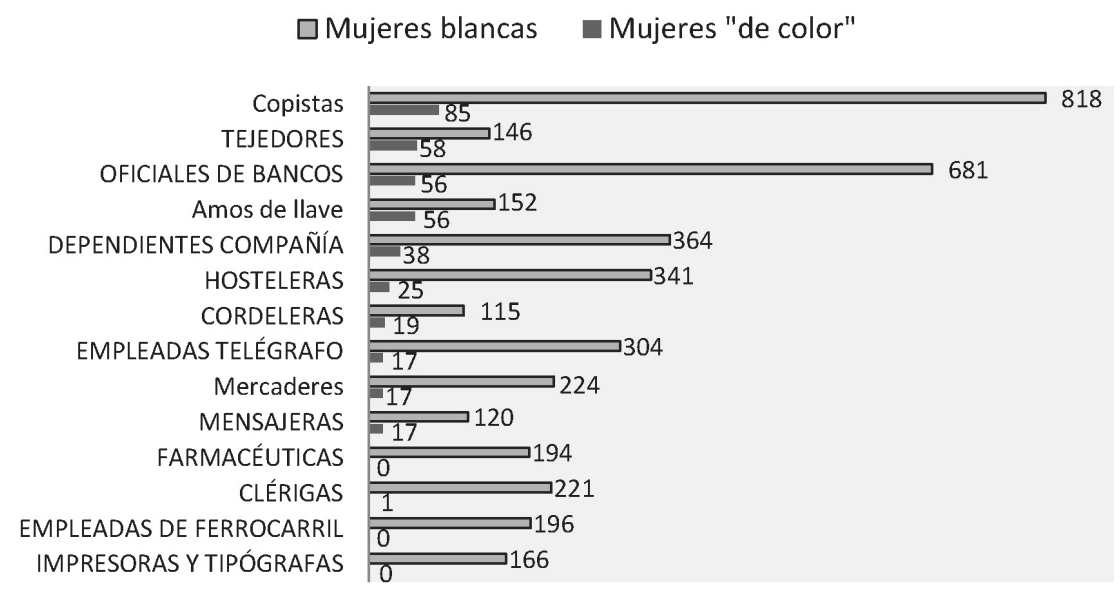

Fuente: censo de 1919. Elaboración propia. 
109.607 empleadas, frente al $28,74 \%$ de las mujeres «de color», con 44.220 trabajadoras. En poco más de veinte años, las mujeres blancas habían duplicado su presencia en todos los sectores, mientras que el número total de mujeres «de color» empleadas se había incrementado solo en mil mujeres respecto a 1919. Englobando a toda la población con empleo, las mujeres afrocubanas apenas significaban el 3\% de la fuerza laboral registrada en toda $\mathrm{Cuba}^{49}$. La mayoría de las mujeres afrocubanas seguían ejerciendo trabajos manuales vinculados a los servicios domésticos o a la agricultura. De hecho, el $67,5 \%$ de las mujeres negras y mestizas aún trabajaban de criadas, cocineras, costureras, agricultoras, lavanderas o tabaqueras, mientras solo el $41 \%$ de las mujeres blancas seguían desempeñando estos oficios (véase gráfico 21).

GRÁFico 21. DistribuCión PORCENTUAL DE EMPLEOS FEMENINOS, POR «RAZA SOBRE EL TOTAL DE EMPLEADAS» (EN OFICIOS CON AL MENOS 100 TRABAJADORAS A NIVEL NACIONAL)

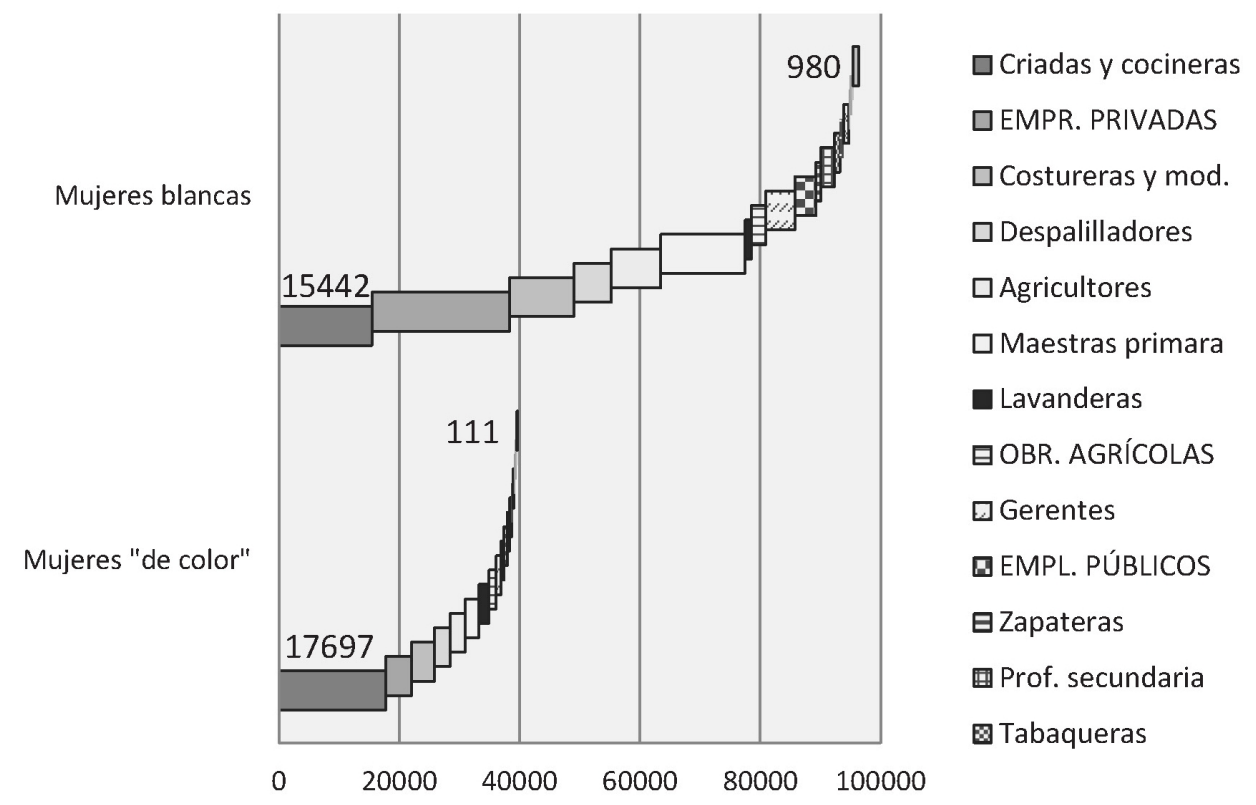

Fuente: censo de 1943. Elaboración propia.

4944.220 «de color» / 1.445 .208 total de la fuerza activa registrada. 
Desde la caída de Machado, pero especialmente durante los años 40', las mujeres afrocubanas comenzaron a ser contratadas en nuevos sectores. 4.297 mujeres negras y mestizas habían pasado a empresas privadas y 514 habían conseguido un contrato en empleos de carácter público. En conjunto esto equivalía al $10 \%$ de todas las mujeres afrocubanas contratadas (véase gráfico 22).

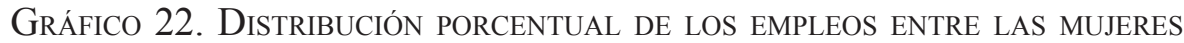
AFROCUBANAS (EN OFICIOS CON AL MENOS 100 MUJERES AFROCUBANAS)

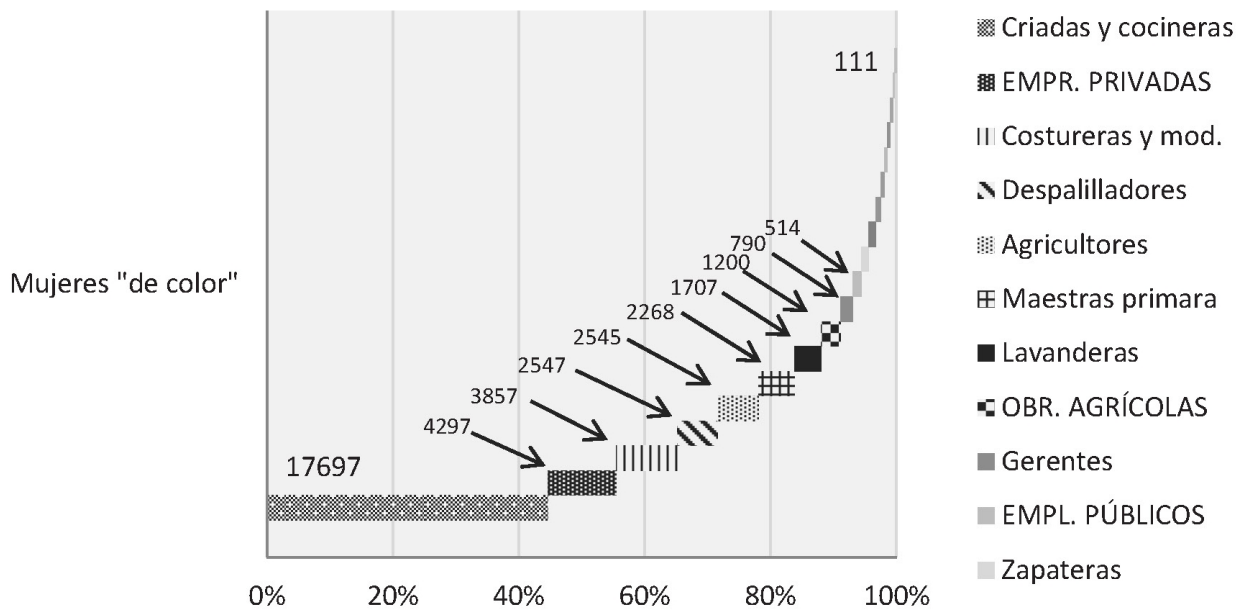

Fuente: censo 1943. Elaboración propia.

No obstante, si bien la mayoría de oficios letrados aún eran ejercidos por los hombres, es posible llegar a constatar la marginación que padecían las mujeres afrocubanas en este campo. El censo de 1943 muestra que había 42 mujeres negras y mestizas impartiendo justicia por 339 mujeres blancas ${ }^{50}$. Además, había 357 farmacéuticas blancas por 32 afrocubanas y esta misma desigualdad se atestigua en otros oficios como enfermeras (685/34), telefonista $(223 / 18)$, agrimensora (159/32), telegrafista (155/6) y dentista $(122 / 32)$. Estos datos permiten afirmar que la incorporación a oficios letrados, el funcionariado y la empresa privada se estaba produciendo de forma despareja entre sendos grupos de mujeres (véanse gráficos 23 y 24).

50 Serrano, 2006: 3-4. 
GrÁFico 23. EmPLeOS CON AL MENOS 100 MUJERES BLANCAS A NIVEL NACIONAL EN COMPARACIÓN CON LAS EMPLEADAS AFROCUBANAS QUE TRABAJABAN EN ESOS MISMOS OFICIOS (EN MAYÚSCULAS LOS OFICIOS DONDE NO HABÍA MUJERES EMPLEADAS O NO SE REGISTRABAN EN EL CENSO DE 1919)

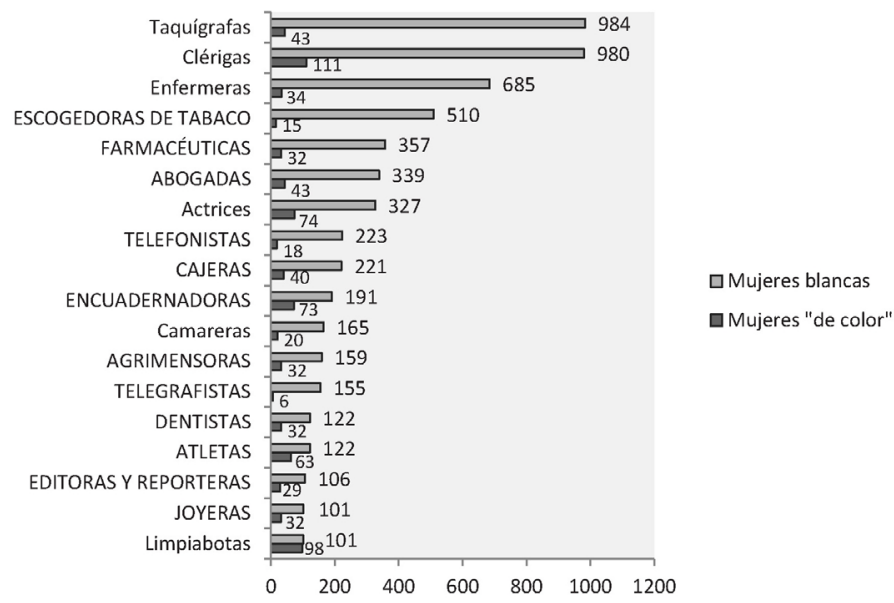

Fuente: 1943. Elaboración propia.

GrÁfico 24. NÚMERo TOTAL DE MUJERES CUBANAS EMPLEADAS, POR OFICIO Y «RAZA» (EN TRABAJOS CON AL MENOS 100 CONTRATADAS A NIVEL NACIONAL)

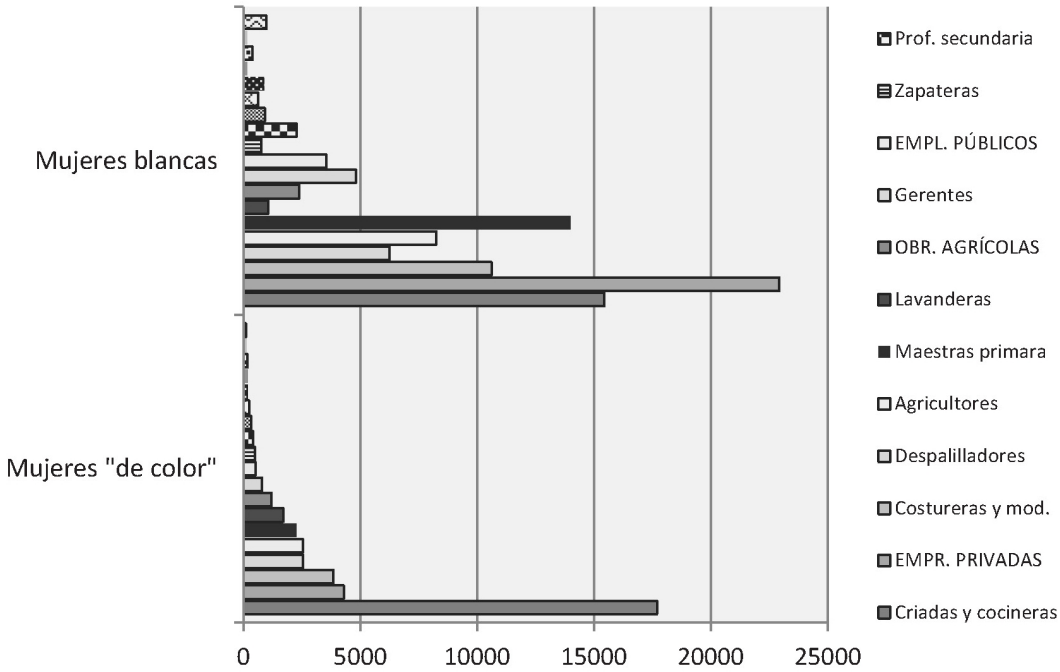

Fuente: censo 1943. Elaboración propia. 
Jorge Ibarra especifica que, en comparación con todas las mujeres empleadas, las mujeres negras habían aumentado su presencia en la industria desde un $10,29 \%$ a un $36,34 \%(+26 \%)$ y en los servicios profesionales, del $1,12 \%$ al $12,9 \%(+11,8 \%)$ (véase gráfico 25$)^{51}$.

\section{Gráfico 25: EVoluCión PORCENTUAL DEL EMPLEO DE MUJERES NEGRAS: 1899-1943}

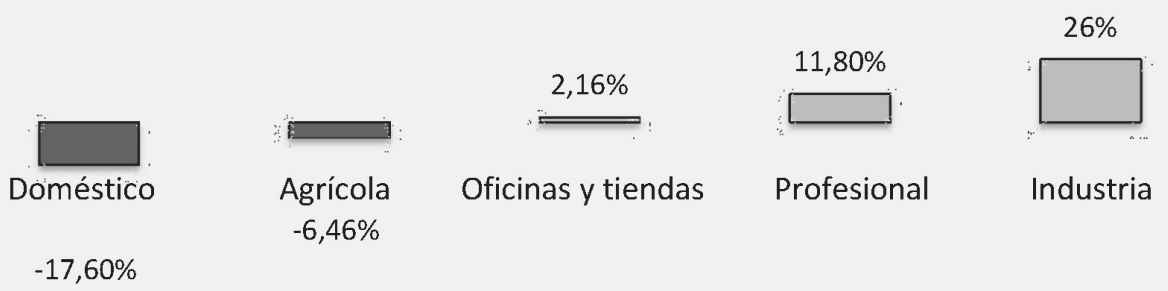

Fuente: Ibarra, 1995: 160-161. Elaboración propia.

Esta tendencia al alza podría responder a la diversificación industrial y el incremento del sector público promovidos por el gobierno de Batista (19401944) $)^{52}$, pero también a la aprobación de la Ley de Nacionalización del Trabajo de 1933, que obligaba a toda empresa instalada en suelo cubano a contratar, por lo menos, un $50 \%$ de mano de obra nacional. Esta medida facilitó la captación de mano de obra cubana, especialmente afrocubana, que se encontraba en paro o realizando actividades ilegales. Sin embargo, la población afrodescendiente continuaba siendo destinada a los oficios más precarios y estuvo poco representada en proporción al total de población activa afrodescendiente (véanse gráficos 26 y 27) ${ }^{53}$. Teniendo en cuenta que la mano de obra femenina era más barata que la masculina cuando ejercían igual oficio, se puede concluir que las mujeres, en concreto las cubanas negras y mestizas,

51 Ibarra Cuesta, 1995: 161.

52 En lo relativo a la incipiente diversificación del sector industrial entre 1933 y 1959 Santamaría, 2000: 514 y 537; 2009: 122.

53 Castellanos y Castellanos, 1990: 352-358. 
resultasen cotizadas para empresas que necesitaban un gran número de empleados, como la industria del azúcar, pero también el tabaco o el textil, de ahí quizás su escasa movilidad laboral ${ }^{54}$.

GRÁfico 26: EVOLUCIÓN PORCENTUAL DEL EMPLEO DE LAS MUJERES «DE COLOR» A LO LARGO DE LA REPÚBliCA (EN OFICIOS CON MÁS DE 100 TRABAJADORAS A NIVEL NACIONAL).

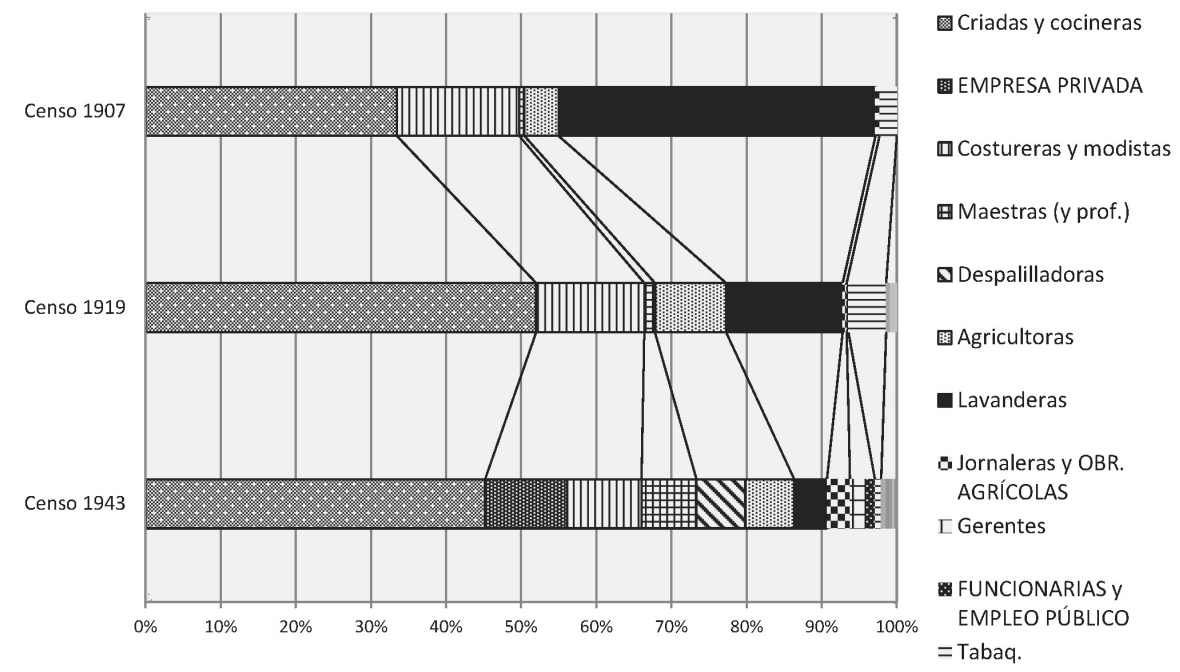

Fuentes: censos de 1907, 1919 y 1943. Elaboración propia.

La desigual integración en el mercado laboral de las mujeres afrocubanas y las mujeres blancas puede tener varias explicaciones: menor nivel de tecnificación y profesionalización, segregación de los contratistas. Sin embargo, cabe la posibilidad de que a lo largo de la república de Cuba las mujeres afrocubanas pasasen a desempeñar con mayor frecuencia labores remuneradas con carácter ilegal, por necesidad y por falta de alternativas. La prostitución o los negocios de carácter familiar donde cobraban de forma extraoficial no se contemplan en los registros censales, pero puede suponerse que esas actividades no requerían cualificación, les procurarían pocos beneficios y no les permitirían ascender en la escala socio-económica.

54 Losada y Vaamonde, 1999: 184. Pérez, 2006: 214. 
GrÁfico 27: COMPARACIÓN DEL EMPLEO TOTAL DE LAS MUJERES «DE COLOR» A LO LARGO DE LA REPÚBLICA (EN OFICIOS CON AL MENOS 100 TRABAJADORAS A NIVEL NACIONAL)

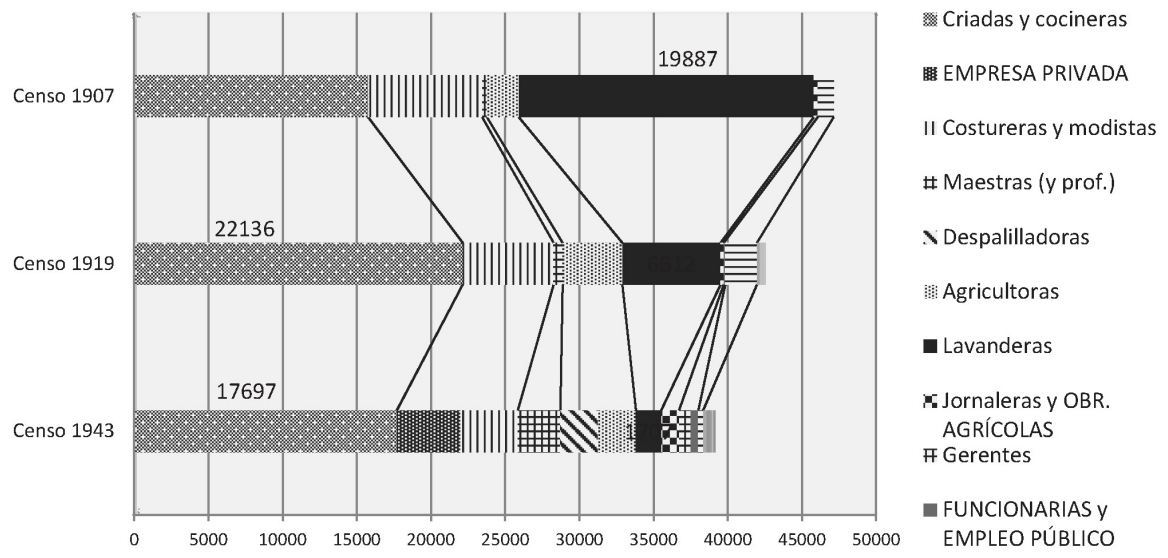

Fuentes: censos de 1907, 1919 y 1943. Elaboración propia.

\section{LA CONQUISTA DE LA CONCIENCIA POLÍTICA DE LA DESIGUALDAD}

La segregación racial en Cuba fue en ascenso desde la instauración de la República. Como se apuntaba anteriormente, el único indicador donde parece haber cierta igualdad entre mujeres blancas y «de color» es en la asistencia a clase y en la alfabetización de las niñas entre 10 y 18 años. Sin embargo, en todos los demás aspectos se atestiguan grandes diferencias, marginación e incluso violencia de carácter político ${ }^{55}$.

Entre 1908 y 1912, el Partido de los Independientes de Color se transformó en un firme opositor a las políticas de conservadores y liberales hacia la población afrocubana. La Ley Morúa prohibió la existencia de partidos construidos sobre criterios raciales, como era el caso del Partido de los Independientes. La tensión entre los diferentes colectivos amenazó la estabilidad socio-económica de la isla y, sobre todo, alertó a los Estados Unidos. Los medios

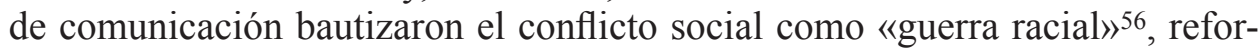

55 La persecución de la brujería, la santería y el ñañiguismo durante el primer cuarto del siglo XX es analizada en Helg (1996) y Naranjo Orovio (2006; 2007).

56 Helg, 1996: 261-266. 
zando así los estereotipos del negro salvaje ${ }^{57}$. Para evitar una nueva intervención norteamericana y como una demostración de fuerza, el presidente José Miguel Gómez consiguió el apoyo de los partidos tradicionales para llevar a cabo la represión del movimiento insurreccional promovido por los Independientes en las provincias orientales contra la citada normativa. La matanza se perpetró entre mayo y junio de 1912. Autores como Fernández Robaina y Aline Helg sitúan las cifras de asesinados entre las 2.000 y 3.000 personas $^{58}$.

A pesar de las muchas proclamas de carácter político, dicha agrupación mantuvo el discurso tradicional sobre las relaciones de género. La única medida de carácter progresista que impulsó fue la aprobación del matrimonio legal entre personas afrodescendientes y el reconocimiento legal de sus hijos. En lo respectivo al papel y la actitud de la mujer, se descubre su lado más tradicional. A través de Previsión, su periódico oficial, reforzó la idea de las mujeres como «ángel del hogar» sometida a la obediencia de su esposo.

Además, se pone para con su marido, en una situación muy difícil. Si éste se enoja, es ridículo, si acepta el hecho, no los es menos; siendo así que él es el jefe de la casa, el editor responsable, el porta-respeto y el desfacedor de agravios. A él toca hacer respetar a la que lleva su nombre y es ponerlo en la imposibilidad de obrar al tratarlo su mujer sin deferencia alguna ${ }^{59}$.

Algunas mujeres negras y mestizas apoyaron de forma activa al PIC en su lucha para derogar esa medida, pero nunca se alzaron en armas junto a sus compañeros ${ }^{60}$. Aunque el programa político de los independientes no contemplaba reivindicaciones específicas para mejorar la situación de las mujeres afrocubanas, estas terminaron uniéndose a la causa. Los Comités de Damas fueron la vía más directa de contribuir a la causa desde la retaguardia. Y $\sin$ embargo, a pesar de su escaso protagonismo en la acción directa armada, varias de sus integrantes fueron apresadas ${ }^{61}$.

La presencia de las mujeres en los partidos políticos oficiales durante la república de Cuba fue nula hasta la caída de Machado en 1933, más aún si cabe en el caso de las mujeres afrocubanas. En 1934 se aprueba el sufragio femenino por decreto. En las elecciones municipales de 1936, ocho mujeres obtuvieron por primera vez cargos como representantes. Y en 1940, la nueva

\footnotetext{
57 González-Ripoll, Naranjo, Ferrer, García Rodríguez y Opatrný, 2004.

58 Torres-Elers, 2013: 124-127.

59 Previsión, 5 de enero de 1909.

60 Archivo Histórico Provincial de Santiago de Cuba (AHPSC), Gobierno Provincial, legajos 49, 1790, 1791 y 1792. Visto en Torres-Elers, 2013: 125.

61 Ibidem: 116-128. Fernández Robaina, 1994: 97-100.
} 
Constitución incorporó el sufragio universal para mayores de 21 años a su articulado. Desde ese momento y hasta 1958 solamente hubo tres senadoras y veintitrés representantes femeninas en el parlamento, como explica Olga Coffigny ${ }^{62}$. Sin embargo, ninguna de estas mujeres era afrodescendiente.

Las agrupaciones feministas y sufragistas defendieron en sus estatutos su naturaleza interracial, pero fueron escasos los ejemplos de mujeres negras y mestizas que integraron sus cúpulas de poder. En 1913, el Partido Nacional Feminista, a pesar de su carácter elitista, proclamaba su afán de luchar por los derechos de todas las mujeres independientemente de su procedencia racial y su estatus económico, al igual que el Club Femenino en 1918 y la Alianza Nacional Femenina desde 1930. Algunas mujeres afrocubanas empezaron a integrar las estructuras de aquellas organizaciones durante el proceso que culminó con la caída de Gerardo Machado en 1933. Sin embargo, hasta donde se sabe, no desempeñaron cargos ejecutivos de relevancia, ni protagonizaron acciones destacables.

Según Takkara Keosha, a partir de 1939 se atiende con mayor detenimiento la exclusión social de las mujeres afrodescendientes. El III Congreso Nacional de Mujeres, convocado antes de la Asamblea Constituyente donde se discutiría sobre la redacción de la Constitución de 1940, constituyó un espacio propicio para plantear reformas legislativas que intentasen paliar la marginación que padecían $^{63}$. Las mujeres afrocubanas participaron en esta reunión. Entre ellas destacan la mujer mestiza, Esperanza Sánchez Mastrapa, representante por el partido Unión Revolucionaria Comunista, de la antigua provincia de Oriente, y María Damasa Jova, activista negra, poeta y pedagoga procedente de Las Villas. En el discurso de apertura del III Congreso Nacional de Mujeres se apuntó la necesidad de discutir sobre el acceso de las mujeres negras a cualquier puesto de trabajo en igualdad de condiciones respecto a las mujeres blancas ${ }^{64}$. Con ese objetivo se estableció una mesa que llevó por título "La mujer y los prejuicios raciales" donde se abordaron los siguientes puntos:

1. Situación de la mujer negra en Cuba. Su problema social, cultural y económico.

2. El prejuicio racial y el niño. Igualdad del niño negro y el niño blanco.

3. Igualdad legal y real de las mujeres negras y blancas en la vida cubana.

4. Los prejuicios raciales y sus manifestaciones en el mundo: lucha contra ellos.

5. Participación de la raza negra en la formación de nuestra nacionalidad ${ }^{65}$.

\footnotetext{
62 Coffigny, 2008: 185-197.

63 Keosha, 2011: 201.

64 Rubiera, 2011: 181.

65 Yáñez, 2003: 94.
} 
La consecuencia más inmediata fue la inclusión de dos medidas favorables para las mujeres afrocubanas en la Constitución de 1940: el sufragio universal y la prohibición de todo tipo de práctica segregacionista. Sin embargo, las acciones xenófobas continuaron siendo denunciadas hasta los años cincuenta por el Club de Atenas y la Federación Nacional de Sociedades de la Raza de Color ${ }^{66}$.

El club y la revista Minerva fueron los órganos más activos de expresión de la población afrodescendiente a comienzos de la República. A medio camino entre la formación, la política y el entretenimiento, durante su segunda etapa ${ }^{67}$ dieron voz a un gran número de mujeres en sus «Páginas feministas». Una de las mayores críticas realizadas al nuevo sistema político era que a pesar de que muchos afrocubanos habían alcanzado altos grados de formación, se les negaba la entrada a determinadas instituciones. En sus publicaciones se hace mención a mujeres negras y mestizas que destacaban por su labor docente, como Úrsula Coimbra o Filomena Berravarza, también a otras mujeres «de color» que participaban en las tertulias de la Sociedad de Estudios Literarios y Científicos de La Habana, como Riga Flores de Campo Marquetti, Inocencia Silveira, Graciela Serra, Cristina Ayala y Digna de Lisle, entre otras ${ }^{68}$.

En lo relativo al asociacionismo enfocado hacia el recreo y la instrucción de la población afrodescendiente, las mujeres negras y mestizas tuvieron mayor protagonismo. Durante toda la república, el Club de Atenas fue la agrupación más relevante entre las integradas por población afrocubana. Como atestigua Leyma Hidalgo, nace por la «necesidad que sentían estos sectores de organizarse para dar cuerpo a sus aspiraciones como grupo social», así como para promover la educación y el recreo de las familias negras y mestizas de La Habana. El Club mantenía la visión de abnegada y sumisa esposa para las mujeres afrodescendientes que asistían ${ }^{69}$. Sin embargo, esta actitud no sería compartida por algunas de sus integrantes. Ejemplo de ello fueron Ángela Rodríguez de Edreira, que obtuvo el grado de sargento durante la Guerra de Independencia. Su hija Angelina Edreira, alcanzó el doctorado en pedagogía, y María Latapier se erigió como directora facultativa de la Sociedad Unión Fraternal ${ }^{70}$.

66 De la Fuente, 2001: 322-324.

${ }^{67}$ La primera etapa: 1888-1889 es estudiada por Carmen Barcia Zequeira en Rubiera y Matiatu, 2011. La segunda etapa corresponde al período 1910-1915 y ha sido abordada por Montejo, 1998.

68 Montejo, 1998: 41.

69 Morrison, 1999; 2000: 84.

70 Hidalgo, 2012: 35. 
En otro orden actuó el Club Maceo de Güines. En sus estatutos fundacionales se describe como agrupación para la instrucción y el recreo. Establece que la asociación solamente aceptará a integrantes «de la raza negra» ${ }^{71}$. En posteriores artículos expone la intención de crear una sección femenina con el mismo criterio, pero se desconoce si finalmente se llevó a efecto ${ }^{72}$.

En la misma línea se fundó el Antilla Sport Club, con un mayor número de actividades y más pervivencia en el tiempo, «para personas de todas las razas». En su reglamento de 1922 se aprueba la fundación de una sección femenina y se procede a ello ${ }^{73}$. Sin embargo, en diciembre de 1933, algunos integrantes de la comisión para la reforma del articulado proponen que se cierre el sector femenino del club. Las mujeres integrantes se opusieron a ello, logrando que se estableciera un Comité de Damas con carácter permanente $^{74}$. En Antilla Sport Club algunas mujeres pudieron desarrollar actividades deportivas tras realizar labores domésticas, una vía alternativa de ascenso social que en el caso de Haydée Claver la llevarían a ser, tiempo más tarde, la primera jugadora afrodescendiente de la selección cubana de baloncesto:

Yo asistía al Club Antillas a jugar al ping pong. Me gustaba. El profesor Gerardo Arago al ver mis condiciones físicas me seleccionaba para integrar el equipo mixto de hombres y mujeres de baloncesto de ese club. [...] en ese tiempo ya tenía 20 años [1949]. Pero eso se dice así fácil, pero yo trabajaba como doméstica por la mañana y por la tarde era que podía entrenar. [...] En muchas ocasiones tuve que ir a esos lugares a pie por no tener dinero para pagar el pasaje de la guagua. Pero todo aquel esfuerzo, sacrificio y dedicación no fue en vano. Pude llegar a la cima y representar a Cuba en diferentes encuentros internacionales en los dos deportes $^{75}$.

Las mujeres afrodescendientes tuvieron cierta presencia, no ya en los partidos, sino en las asociaciones o agrupaciones con carácter político. Para ilustrar esta problemática, se tomarán dos ejemplos. Adelante, Asociación Pro-Cultura y Justicia fue creada en 1934 con el objetivo de luchar por las reivindicaciones de un sector social «que hoy no las disfruta», si bien advertían sobre su carácter no racista contra la población blanca para desligarse de

71 Club Maceo de Güines, 27 de septiembre de 1919, Archivo Nacional de Cuba, La Habana (ANC), Registro de Asociaciones, legajo 1195, exp. 24959: 6.

72 Ibidem: 13.

73 Antilla Sport Club, 10 de agosto de 1922, ANC, Registro de Asociaciones, legajo 342, exp. 10180: 23

74 Ibidem: 50.

75 Testimonio de Haydée Claver Larrinaga, reproducido en Rubiera y Matiatu, 2011: 349. 
todo lo relativo al $\mathrm{PIC}^{76}$. En la documentación que se conserva sobre esta agrupación, se mencionan algunos gastos «por concepto del Comité de Damas» ${ }^{77}$. Lo cierto es que Adelante criticó la discriminación por «raza» y sexo. A la par, las mujeres afrocubanas se movilizaron por su cuenta y crearon unos «comités de defensa de las mujeres» desde los cuales presionaron a la propia institución para incrementar la presencia de mujeres en la organización. ${ }^{78}$ Lo cierto es que, durante los años 30', llegaron a ocuparse de la secretaria general y la tesorería y a partir de 1940 desempeñaron otros cargos de forma puntual, pero los puestos ejecutivos principales siempre recayeron en manos de varones ${ }^{79}$.

Por su parte, el Frente Cívico Cubano Contra la Discriminación se fundó en febrero de 1952, solo un mes antes del golpe de Estado perpetrado por Batista. La agrupación sobrevivió durante cuatro años, aunque no dejó demasiada documentación de la actividad que llevó a cabo, quizás por la coyuntura histórica que atravesaba Cuba tras haber sido anuladas las garantías constitucionales. En su reglamento fundacional afirma que su objetivo era luchar «por el mejoramiento económico, social y cultural de toda la ciudadanía que por razón de su raza ó coloración epidérmica, sufre los rigores de la discriminación, ya sea para el trabajo ó cualquier otro fin de la vida cotidiana» ${ }^{80}$. La primera candidatura que fue elegida para dirigir la asociación integraba a seis mujeres en puestos de relevancia, como la secretaría de cultura o las relaciones internacionales. Cuatro de ellas habían alcanzado el grado de «doctoras». Si bien resulta imposible saber su procedencia racial, lo cierto es que al menos integraron una organización política que pretendía luchar contra la segregación en Cuba. Esto tiene aún más relevancia si se considera que a lo largo de la documentación generada, se habla sobre la existencia de un Comité de Asuntos Femeninos que, presumiblemente, concentraría sus esfuerzos en luchar por el mejoramiento de la situación de marginalización que padecían las mujeres afrodescendientes. El artículo 40, de hecho, apunta que sus objetivos serían «organizar a la mujer cubana en todo el país a través de las delegaciones locales y provinciales, así como estimular y desarrollar las activi-

76 Adelante. Asociación pro-cultura y justicia, 19 de septiembre de 1933, ANC, Registro de Asociaciones, legajo 6243, exp. 237: 1.

77 Ibidem: 22-25 de diciembre de 1940: 77.

78 De la Fuente, 2000: 282.

79 Adelante. Asociación pro-cultura y justicia, 25 de diciembre de 1940, 14 de noviembre de 1941 y 1 de enero de 1942, ANC, Registro de Asociaciones, legajo 6243, exp. 237: 80, 88 y 92.

80 Frente Cívico Cubano Contra la Discriminación, marzo de 1952, ANC, Registro de Asociaciones, legajo 3736, exp. 181: 9. 
dades que sean necesarias para la superación cultural y física de la mujer cubana» ${ }^{81}$.

\section{CONCLUSIONES: LAS LIMITADAS CONQUiSTAS DE LAS MUJERES AFROCUBANAS}

En términos generales, las mujeres cubanas experimentaron mejoras en el ámbito civil, político y laboral durante la república de Cuba, entre 1902 y 1959. Sin embargo, favoreció de forma desigual a mujeres blancas y afrodescendientes. Como se ha visto, ambas incrementaron sus índices de alfabetización tras la abolición de la esclavitud y gracias a la implementación de la educación básica obligatoria. Además, las mujeres negras y mestizas asistieron de media a clase el mismo tiempo que las estudiantes blancas, al menos hasta los dieciocho años.

La aparente igualdad en la formación básica no tuvo su contrapartida en la educación superior ni en el terreno laboral. En términos porcentuales, las mujeres de ambos colectivos se licenciaban en carreras parecidas, pero en términos absolutos más mujeres blancas obtuvieron titulaciones superiores, incluso a final del período republicano. Aquí podría constatarse la diferencia económica que mediaba entre ambos grupos raciales. La ley que reorganizaba la segunda enseñanza y la educación superior en 1936 estableció que la universidad solamente concedería matrículas gratuitas en «cantidad no mayor al 20 por ciento del total de sus matrículas regulares o efectivas» ${ }^{82}$. Esto suponía un obstáculo para muchas alumnas negras y mestizas de secundaria que aspiraban a continuar su formación académica. Si bien es cierto que existía una llamada «burguesía negra» que podía permitirse costearse las tasas universitarias, la mayoría de la población afrocubana no poseía los ingresos mínimos necesarios, y no todas eran admitidas debido al número limitado de plazas que se ofertaban.

Este puede ser uno de los motivos que llevó a las mujeres negras y mestizas a continuar trabajando en sectores vinculados con el antiguo sistema esclavista. Si bien el 10\% de todas las empleadas afrocubanas se introdujeron en la industria, los empleos públicos y la empresa, el 67,5\% continuaba trabajando en oficios manuales relacionados con la agricultura o los servicios domésticos. Además, las cifras totales de empleo registrado en 1943 permiten afirmar que durante la República las mujeres negras y mestizas pasaron de constituir el $6,04 \%$ al $2,37 \%$ de toda la fuerza laboral registrada a nivel na-

\footnotetext{
81 Ibidem: 14.

82 Pichardo, IV, 1986: 119.
} 
cional. La desigual integración en el mercado laboral de las mujeres afrocubanas y las mujeres blancas puede tener varias explicaciones: menor nivel de tecnificación y profesionalización, segregación de los contratistas. Sin embargo, cabe la posibilidad de que a lo largo del período republicano las mujeres afrocubanas fueran empujadas con mayor frecuencia hacia el mundo de la prostitución o los negocios de carácter familiar que formaban parte de la economía sumergida.

Algunas vías de expresión adoptadas por las mujeres afrodescendientes en su expansión hacia el espacio público fueron el Partido Independiente de Color, las asociaciones de recreo e instrucción y las asociaciones políticas. En el PIC las mujeres negras y mestizas se limitaron a desempeñar labores de proselitismo y apoyo logístico de las actividades que realizaron sus maridos. A pesar de que los varones lucharon por los derechos de la «raza» negra, seguían defendiendo el modelo tradicional de la mujer como sumiso «ángel del hogar». Años después, la creciente burguesía afrocubana comenzó a fundar agrupaciones con carácter más o menos endogámico para elevar el nivel cultural de su «raza» o fomentar el ocio de su membresía. Algunas tuvieron un carácter combativo, como Adelante, pero sus proclamas oficiales no se materializaron en mejoras prácticas para la población afrodescendiente en general, menos aún para el sector femenino.

La participación política de las mujeres afrodescendientes pareció ser irregular y poco destacable entre 1902 y 1959. Por lo general, los movimientos femeninos y sufragistas se definieron como interraciales, pero raramente integraron en sus filas a mujeres negras y mestizas, a excepción de agrupaciones como la Unión Radical de Mujeres en 1931. Se desconoce si esto se debe a la discriminación activa de sus dirigentes, a que las mujeres afrocubanas eran un sector social escasamente activo en política o a alguna otra razón. El caso es que hasta 1925 únicamente asistieron mujeres blancas a los congresos y reuniones femeninas de proyección nacional y solo en 1939 un Congreso Nacional de Mujeres propuso la discriminación de las mujeres afrocubanas como objeto de discusión. Además, a pesar de que la constitución de 1940 prohibía las prácticas segregacionistas, durante el segundo período constituyente no hubo senadoras, ni representantes parlamentarias negras o mestizas.

Podría argumentarse que estas restricciones estaban relacionadas con su nivel formativo o su poder adquisitivo, debido a que la universidad no era gratuita. Sin embargo, se ha visto que a la altura de 1943 ya se había equiparado el nivel de alfabetización entre las mujeres blancas y afrocubanas, y en términos porcentuales se licenciaban en carreras similares. La población afrocubana, en general y en términos porcentuales, desempeñaba oficios que requerían peor cualificación, pero había excepciones. Bajo el gobierno de Ba- 
tista (1940-1944) y (el Partido Revolucionario Cubano Auténtico (1944-1948) se puede atestiguar la presencia de algunas mujeres negras y mestizas ocupando puestos administrativos, desempeñando cargos públicos y ejerciendo profesiones como la abogacía, pero suponían una minoría.

Para entender la ausencia de las mujeres afrocubanas en los aparatos de poder podría aludirse a la reproducción de los esquemas simbólicos y patriarcales ${ }^{83}$ o al concepto «techo de cristal» ${ }^{84}$. En parte se debía a la exclusión que las mujeres, como género, padecían frente a los hombres a nivel estructural, tanto en los espacios públicos como privados. Sin embargo, a esta explicación escapa el hecho de que las mujeres negras y mestizas no tuvieron acceso a carreras universitarias, puestos laborales y organizaciones donde las mujeres blancas ingresaron con mayor facilidad, fueron mayoría o incluso constituían la totalidad de sus integrantes.

Según lo expuesto en este artículo, el racismo heredado del período colonial y perpetuado por diferentes instancias académicas, sociales y políticas parecía seguir vigente a la altura de $1943^{85}$. Por lo tanto, resulta pertinente

83 La reproducción de los esquemas patriarcales y las estructuras simbólicas del poder se analizan en Bourdieu, 2000, 120-136, quien en otro momento afirma que «[...] la dominación masculina tiene todas las condiciones para su pleno ejercicio. La preeminencia universalmente reconocida a los hombres se afirma en la objetividad de las estructuras sociales y de las actividades productivas y reproductivas, y se basa en una división sexual del trabajo de producción y de reproducción biológico y social que confiere al hombre la mejor parte, así como en los esquemas inmanentes a todos los hábitos/bichos esquemas, construidos por unas condiciones semejantes, y por tanto objetivamente acordados, funcionan como matrices de las percepciones - de los pensamientos y de las acciones de todos los miembros de la sociedad-, trascendentales históricas que, al ser universalmente compartidas, se imponen a cualquier agente como trascendentes», Bourdieu, 2000: 49.

${ }^{84}$ El concepto «techo de cristal» se explica en Valcárcel, 1997: 89-113, por ejemplo cuando afirma: «Con la expresión 'techo de cristal' se designa todo el conjunto de prácticas y maniobras que dan como resultado que las mujeres sean desestimadas por los sistemas de cooptación. Y existe un sistema de cooptación cuando, añadido a los elementos expertos, concurre un criterio no experto de adecuación superior a éstos. Los dos grandes subsistemas de los que se alimenta toda la trama organizacional del poder son la libre concurrencia y la cooptación. En la práctica algunos casos de libre concurrencia son cooptaciones: es el caso de cuerpos muy restringidos que mantengan gran influencia. Estamos ante la libre concurrencia cuando de lo que se trata es de probar la existencia de una habilidad, una expertisse cualquiera cuya prueba sea objetivable. [...] Y estamos ante un sistema de cooptación cuando al lado de la red formal existe una red informal poderosa y se juzga no sólo la habilidad en todo caso requerida, sino un elemento no experto de adecuación que sólo quienes proveen el puesto pueden distinguir en el candidato o candidata».

85 Sobre la construcción social del racismo y su perpetuación en las sociedades occidentales, ver Foucault, 1998. Acerca del racismo en Cuba tras la Guerra de Independencia de 1898, Naranjo Orovio, 1996; 2006; 2007. Naranjo Orovio y García, 2000. García y Álvarez, 
aludir al término «capitalismo patriarcal racialmente estructurado», concebido para denunciar toda aquella "violencia racista estatal [...] experiencias de explotación y opresión de las mujeres de color en el Sur [...] en esa intersección entre colonialismo, imperialismo y capitalismo global» ${ }^{86}$. En términos generales, las mujeres afrocubanas padecieron los efectos de la descolonización característicos de las naciones que habían abolido el sistema esclavista: gran número de mano de obra desocupada, emigración desde el campo a la ciudad, inadaptación e incapacidad para integrarse en el mundo urbano, bajo índice de alfabetización, empleos precarios y mal remunerados que requerían escasa cualificación, incapacidad de articularse como colectivo, mediante asociación o partido político, e imposibilidad de promocionar en la escala social. Hasta el final de la república, las mujeres afrocubanas desempeñaron oficios que habían venido desarrollando durante el período colonial. En este contexto, el paradigma patriarcal de la mujer recluida en casa se perpetuó y vino a sancionar su rol como criadora y educadora de sus hijos. A esto habría que añadir, no solo el racismo que la población blanca mantuvo en general contra la población negra y mestiza, sino el racismo que en particular practicaron de forma consciente o inconsciente la mayoría de agrupaciones feministas. Estos conflictos sociales potenciaron los efectos del «techo de cristal» que afectaba a la mitad de la población y actuó como el doble freno que limitó la proyección hacia el espacio público de las mujeres negras y mestizas

\section{BiBLIOGRAFÍA}

Ali, Asghar Azra, The emergence of feminism among indian muslim women, 19201947, Karachi, Oxford University press, 2000.

Ameringer, Charles D., The Cuban democratic experience: the Autentico years, 19441952, Gainsville, University Press of Florida, 2000.

Amorós, Celia, Teoría feminista: de la ilustración a la globalización, vol. 2. Del feminismo liberal a la posmodernidad, Madrid, Minerva Ediciones, 2005.

Anderson, Bonnie S. y Zinsser, Judith P., Historia de las mujeres: una historia propia, Barcelona, Crítica, 2007.

2007. Para conocer la cuestión del racismo materializada en la delincuencia femenina, Bronffman, 2007.

86 Bidaseca, 2012: 2. Para profundizar en este marco conceptual: Spivak, 1998. Bhavnani y Culson, 2004. 
Asamblea Constituyente, Diario de Sesiones de la convención constituyente de la Isla de Cuba, La Habana, 1902.

Barcia Zequera, Carmen, Capas populares y modernidad en Cuba, 1878-1930, La Habana, Editorial de Ciencias Sociales, 2009.

Betancourt Milanés, Débora y Molina Piñeiro, Maricela, "La lucha de la Mujer por sus Derechos. Índice temático", La Habana, 1987. [Tesis doctoral inédita conservada en el Instituto de Historia de Cuba].

Bhavnani, Ku-Kum y Coulson, Margaret, "Transformar el feminismo socialista. El reto del racismo", Otras inapropiables. Feminismos desde las fronteras, Madrid, Traficantes de sueños, 2004: 51-63.

Bidaseca, Karina, "Voces y luchas contemporáneas del feminismo negro. Corpolíticas de la violencia sexual racializada", Afrodescendencia. Aproximaciones contemporáneas de América latina y el Caribe, México, ONU, 2012. Colección de ensayos del Centro de Información de las Naciones Unidas para México, Cuba y República Dominicana, en el marco del Año Internacional de los Afrodescendientes.

Bourdieu, Pierre, La dominación masculina, Barcelona, Anagrama, 2000.

Bronffman, Alejandra, "The Allure of Technology: Photographs, Statistics and the Elusive Female Criminal in 1930s Cuba", Gender \& History, XIX/1 (abril 2007): 60-77.

Brown, Nikki, Private politics and public voices: Black women's activism from World War I to the New Deal, Bloomington, Indiana University Press, 2006.

Castellanos, Isabel y Castellanos, Jorge, Cultura afrocubana. vol. 2, El negro en Cuba. 1845-1959, Miami, Ediciones Universal, 1990.

Censo de Población de la República de Cuba 1907 bajo la administración provisional de los EE.UU, Washington, Oficina del Censo de los EE.UU., 1908.

Censo de la República de Cuba, año de 1919, La Habana, Maza, Arroyo y Caso, 1921.

Censo de 1943 de la República de Cuba, La Habana, Fernández y Cía, 1945.

Censos de población, viviendas y electoral, 1953, La Habana, Dirección General del Censo, 1953.

Cento Bull, Anna; Diamond, Hanna y Marsh, Rosalind J., Feminisms and women's movements in contemporary Europe, New York, St. Martin's Press, 2000.

Coffigny Leonard, Olga, "Mujeres parlamentarias cubanas (1936-1958)", Temas, 55 (La Habana, julio-septiembre 2008): 185-197.

De la Fuente, Alejandro, Una nación para todos. Raza, desigualdad y política en Cuba, 1900-2000, Madrid, Editorial Colibrí, 2000. 
Duby, George y Pierrot, Michelle, Historia de las mujeres en Occidente, vol. 4 El siglo XIX y vol. 5 El siglo XX, Madrid, Taurus, 2000.

Fernández Robaina, Tomás, Bibliografía de temas afrocubanos, La Habana, Biblioteca Nacional José Martí, 1985.

Fernández Robaina, Tomás, El negro en cuba. 1902-1958, La Habana, Editorial de Ciencias Sociales, 1994.

Foucault, Michel, Genealogía del racismo, La Plata, Caronte Ensayos, 1998.

García González, Armando y Álvarez Peláez, Raquel, Las trampas del poder. Sanidad, eugenesia y migración: Cuba y Estados Unidos (1900-1940), Madrid, CSIC, 2007.

García González, Armando, En busca de la raza perfecta. Eugenesia e higiene en Cuba (1898-1958), Madrid, CSIC, 1998.

Glickman, Rose L., Russian factory women: workplace and society 1880-1914, Los Angeles, University of California Press, 1984

González González, José Pedro y Reyes Velázquez, Raúl, "Desarrollo de la Educación en Cuba después del año 1959", Revista Complutense de Educación, XXI/1 (Madrid, 2010): 13-35.

González Pagés, Julio, En busca de un espacio: Historia de mujeres en Cuba, La Habana, Editorial de Ciencias Sociales, 2003.

González-Ripoll, María Dolores; Naranjo, Consuelo; Ferrer, Ada; García Rodríguez, Gloria y Opatrný, Josef, El rumor de Haití en Cuba, Madrid, CSIC, 2004.

Helg, Aline, "Políticas raciales en Cuba después de la independencia: Represión de la cultura negra y mito de la igualdad racial", América Negra, 11 (Bogotá, 1996): 63-83.

Helg, Aline, Lo que nos corresponde. La lucha de los negros y mulatos por la igualdad en Cuba. 1886-1912, La Habana, Imagen Contemporánea, 2000.

Hidalgo, Leyma, "El Club Atenas y la cuestión racial: boletín y revista de 1917 a 1931”, Iberoamericana Global, V/2 (Jerusalem, 2012): 30-45.

Huerta Martínez, ángel, "La educación de la mujer en la isla de Cuba en vísperas de la revolución Independentista", Mujer y educación en España, 1868-1975. VI Coloquio de Historia de la Educación, Santiago, Universidad de Santiago de Compostela, 1990: 474-481.

Julian Spruill, Marjorie, New women of the new South: the leaders of the woman suffrage movement in the southern states, New York, Oxford University Press, 1993.

Keosha Brunson, Takkara, "Constructing Afro-Cuban Womanhood: Race, Gender, and Citizenship in Republican-Era Cuba, 1902-1958”, Tesis Doctoral, University of Austin, Texas, 2011. Consultado en http://repositories.lib.utexas.edu/bitstream/ 
handle/2152/ETD-UT-2011-08-4213/BRUNSON-DISSERTATION.pdf? sequen$c e=1$ (Fecha de consulta 20-09-2014).

Kingsley Kent, Susan, Sex and suffrage in Britain, 1860-1914, London, Routledge, 1990.

Kraditor, Aileen S., The ideas of the woman suffrage movement (1890-1920), New York, Norton, 1981.

Lamar, Hortensia, "Problemas nacionales", La mujer moderna (La Habana, noviembre de 1925a): 25-27.

Lamar, Hortensia, "Nuestra labor", La mujer moderna (La Habana, noviembre de 1925b): 34-35.

Lamar, Hortensia, "Lucha contra el alcoholismo", La mujer moderna (La Habana, febrero de 1926): 27.

Liz Ortiz-Loyola, Brenda, "En busca de la solidaridad: feminismo y nación en el Caribe hispano, 1880-1940", Tesis Doctoral, University of California, 2013. Consultado en http://escholarship.org/uc/item/0x63r40z (Fecha de consulta 20-09-2014).

Losada Álvarez, F., Vaamonde Porto, "Nacionalidad y ciudadanía. La concesión de cartas de naturalización a los españoles en Cuba", Historia Contemporánea, 19 (País Vasco, 1999): 181-196.

Lynn Stonner, Katherine, De la casa a la calle. El movimiento cubano de la mujer en favor de la reforma legal (1898-1940), La Habana, Editorial de Ciencias Sociales, 2003.

McCrone, Kathleen E., Sport and the physical emancipation of English women, 18701914, London, Routledge, 1988.

McMillan, James F., France and women, 1789-1914: gender, society and politics, London-New York, Routledge, 2000.

Mead, Rebecca J., How the vote was won: woman suffrage in the western United States, 1868-1914, New York, New York University Press, 2004.

Memorias inéditas del Censo de 1931, La Habana, Editorial de Ciencias Sociales, 1978.

Montejo, Carmen, "Minerva. A Magazine for Women (and Men) of color", Lisa Brocky y Digna Castañeda Fuertes (ed.), Between race and empire: African, Philadelphia, Temple University Press, 1998: 33-49.

Montejo, Carmen, Sociedades negras en Cuba: 1878-1960, La Habana, Editorial de Ciencias Sociales-Centro de Investigación y Desarrollo de la Cultura Cubana Juan Marinello, 2004.

Morrison, Karen Y., "The Limits of Patriarchal Imitation: Reading Gender from a 1915 Afro-Cuban Text: Views from 'Palpitaciones de la Raza de Color'”, ponen- 
cia presentada en la Conference of Latin American Historians, Washington, D.C., 7 de enero de 1999.

Morrison, Karen Y., "Civilization and Citizenship through the eyes of Afro-Cuban Intellectuals during the First Constitutional Era, 1902-1940”, Cuban Studies, 30 (Pittsburg, 2000): 76-96.

Naranjo Orovio, Consuelo y García González, Armando, Medicina y racismo en Cuba: la ciencia ante la inmigración canaria en el siglo XX, La Laguna, Tenerife, Centro de la Cultura Popular Canaria, 1996.

Naranjo Orovio, Consuelo, “Antropología, 'raza' y población en Cuba en el último cuarto del siglo XIX”, Anuario de estudios americanos, 55/1 (Sevilla, 1998): 267289.

Naranjo Orovio, Consuelo y Santamaría, Antonio, "El 98 en América. Últimos resultados y tendencias recientes de la investigación”, Revista de Indias, LIX/215 (Madrid, 1999): 203-273.

Naranjo Orovio, Consuelo, "La historia social de Cuba, 1868-1914. Aportaciones recientes y perspectivas", Historia Social, 33 (Barcelona, 1999): 133-158.

Naranjo Orovio, Consuelo y García González, Armando, "Blanqueamiento, 'higiene racial' y exclusión en Cuba”, Espace Caraïbe Amériques, 1 (París/Guyane, 2000): 167-182.

Naranjo Orovio, Consuelo, "De la esclavitud a la criminalización de un grupo: la población de color en Cuba", Nuevo Mundo Mundos Nuevos, 6, online (2006). http://nuevomundo.revues.org/2019. (Fecha de consulta: 09/19/2014).

Naranjo Orovio, Consuelo, "El peso de la esclavitud en Cuba: miedo y recelos contra una población", Josef Opatrný (ed.), Pensamiento caribeño. Siglos XIX y XX, Praga, Universidad Carolina de Praga Karolinum, 2007: 313-326. Serie Ibero-Americana Pragensia, Supplementum.

Nascimiento, Rosita, "La educación en Cuba", Historia de la educación en Iberoamérica (1945-1992), vol. 1, Buenos aires, Miño y Dávila, 1995: 197-229.

Núñez Sarmiento, Marta, "Los estudios de género en Cuba y sus aproximaciones metodológicas, multidisciplinarias y transculturales (1974-2001)", La Habana, Centro de Estudios de Migraciones Internacionales, 2002. Visto en la Biblioteca Virtual de CLACSO: http://bibliotecavirtual.clacso.org.ar/ar/libros/cuba/cemi/ genero.pdf (Fecha de consulta: 03-10-2014).

Oficina del Censo de los Estados Unidos, Censo de la República de cuba, 1907, Washington, D.C., Government Printing Office, 1908.

O'Brien, Thomas F., The Revolutionary mission. American Enterprise in Latin America, 1900-1945, Cambridge, Cambridge University Press, 1999.

Pérez Garzón, Juan Sisinio, Historia del feminismo, Madrid, Catarata, 2011. 
Pérez, A. Luis, Cuba: between reform and revolution, Nueva York, Oxford University Press, 2006.

Pichardo, Hortensia, Documentos para la Historia de Cuba, La Habana, Editorial Pueblo y Educación, 1986.

Pignot, Elsa, "El asociacionismo negro en Cuba: una vía de integración en la sociedad republicana (1920-1960)", Revista de Indias, LXX/250 (Madrid, 2010): 837862.

Rivera Pérez, Aymée, "El imaginario femenino negro en Cuba", AFROEUROPA: Journal of Afroeuropean Studies I/2 (2007). http://journal.afroeuropa.eu/index. php/afroeuropa/issue/view/2 (Fecha de consulta 03-10-2014)

Roth, Benita, Separate roads to feminism: black, Chicana and white feminist: movements in America's second wave, Cambridge, Cambridge University Press, 2004.

Rubiera Castillo, Daisy y De los Reyes Castillo, María, Reyita, sencillamente: testimonio de una negra cubana nonagenaria, La Habana, Instituto Cubano del Libro, 1997.

Rubiera Castillo, Daisy, "Apuntes sobre la mujer negra en Cuba”, Cuban Studies, XXII (Pittsburgh, 2011): 176-185.

Rubiera, Daisy y Matiatu, Inés María, Afrocubanas: historia, pensamiento y prácticas culturales, La Habana, Editorial de Ciencias Sociales, 2011.

Santamaría, Antonio, “El crecimiento económico de Cuba republicana (1902-1959). Una revisión y nuevas estimaciones en perspectiva comparada (población, inmigración golondrina, ingreso no azucarero y producto nacional bruto)", Revista de Indias, LX/219 (Madrid, 2000): 505-545.

Santamaría, Antonio, “Evolución económica, 1700-1959”, Consuelo Naranjo Orovio (coord.), Historia de Cuba, Consuelo Naranjo Orovio (dir.), vol. 1, Historia de las Antillas, Madrid/Aranjuez, CSIC/Doce-Calles, 2009: 69-129.

Serrano Peralta, Lourdes, "Mujer, instrucción, ocupación y color de la piel: estructura y relciones raciales en un barrio popular de La Habana", Revista Española de Política Africana y Sociología, 3 (Costa de Marfil, octubre 2006): Reproducido en http://repaso.org/home.html (Fecha de consulta 15-09-2014).

Serviat, Pedro, El problema negro y su solución definitiva, La Habana, Editorial Política, 1986.

Sharp, Ingrid y Stibbe, Matthew, Aftermaths of war: women's movements and female activists, 1918-1923, Boston, Brill, 2011.

Smitley, Megan, The feminine public sphere: middle-class women in civic life in Scotland, 1870-1914, Manchester, Manchester University Press. 2009

Spviak, Gayatri Chakravorty, “¿Puede hablar el sujeto subalterno?”, Orbis Tertius, 6 (La Plata, 1998): 175-235. 
Stonner, Lynn y González, Mario, Minerva: Revista quincenal dedicada a la Mujer de Color, La Habana, Instituto de Historia de Cuba, 1998.

Stonner, Lynn, De la casa a la calle: el movimiento cubano de la mujer a favor de la reforma legal (1898-1940), La Habana, Colibrí, 2003.

Torres-Elers, Damaris A., "Santiagueras en el alzamiento de 1912: ¿leyenda o realidad?", Santiago (Santiago de Cuba, enero-abril 2013): 116-128.

Valcárcel, Amelia, La política de las mujeres, Madrid, Ediciones Cátedra, 1997.

Whitney, Robert, Estado y revolución en Cuba, La Habana, Editorial de Ciencias Sociales, 2010.

Yáñez, Mirta, Camila y 'Camila', La Habana, Ediciones La Memoria, 2003.

Fecha de recepción: 12 de junio de 2013.

Fecha de aceptación: 15 de septiembre de 2013.

\section{Doubly Subjugated: "Colored Women" in the Republic of Cuba (1902-1959)}

This study analyzes the development of afro-descendant women during the Republic of Cuba (1902-1959). First of all, works dedicated to Cuban women as a gender are assessed on one hand and to Afro culture on the other in order to show the extent to which Afro-Cuban women have been neglected by historiography. Then black and mixed-race women are studied in relation to the entire male population and white women. The text is divided into three parts: educational areas, vocational integration and political mobility. The data enables us to affirm that Afro-Cuban women were doubly subjugated throughout the Republican period, because of their gender against men, and because of race against white women.

KEY Words: afro-cuban; Republic of Cuba; gender; race; feminism. 